\title{
Molecular targets for antifungals in amino acid and protein biosynthetic pathways
}

\author{
Aleksandra Kuplińska ${ }^{1}$ Kamila Rząd ${ }^{1}[0$
}

Received: 1 March 2021 / Accepted: 17 May 2021 / Published online: 3 June 2021

(c) The Author(s) 2021

\begin{abstract}
Fungi cause death of over 1.5 million people every year, while cutaneous mycoses are among the most common infections in the world. Mycoses vary greatly in severity, there are long-term skin (ringworm), nail or hair infections (tinea capitis), recurrent like vaginal candidiasis or severe, life-threatening systemic, multiorgan infections. In the last few years, increasing importance is attached to the health and economic problems caused by fungal pathogens. There is a growing need for improvement of the availability of antifungal drugs, decreasing their prices and reducing side effects. Searching for novel approaches in this respect, amino acid and protein biosynthesis pathways appear to be competitive. The route that leads from amino acid biosynthesis to protein folding and its activation is rich in enzymes that are descriptive of fungi. Blocking the action of those enzymes often leads to avirulence or growth inhibition. In this review, we want to trace the principal processes of fungi vitality. We present the data of genes encoding enzymes involved in amino acid and protein biosynthesis, potential molecular targets in antifungal chemotherapy, and describe the impact of inhibitors on fungal organisms.
\end{abstract}

Keywords Antifungal targets $\cdot$ Amino acid biosynthesis $\cdot$ Protein biosynthesis $\cdot$ Candida $\cdot$ Aspergillus $\cdot$ Plant pathogens

\section{Introduction}

Invasive fungal mycoses may affect over 300 million people each year (Stop neglecting fungi 2017; Rodrigues and Nosanchuk 2020) and are responsible for the death of 1.5 million individuals globally (Bongomin et al. 2017), which corresponds to the number of people living in Warsaw, the capital city of Poland. If these estimates are true, it means that in the last 7 months disseminated mycoses caused 875,000 deaths. Skin and nail mycoses affect $20-25 \%$ people in the world, which makes them one of the most frequent forms of infection (Havlickova et al. 2008). Fungal diseases are caused by many species, however, $90 \%$ of fatal cases result from infections caused by species belonging to the genera of Aspergillus, Candida, Cryptococcus and Pneumocystis (Brown et al. 2012). The mortality rate for candidemia

Handling editor: S. Broer.

Kamila Rząd

kamrzad@pg.edu.pl

1 Department of Pharmaceutical Technology and Biochemistry and BioTechMed Center, Gdańsk University of Technology, Gdańsk, Poland is approximately $30-55 \%$ and $50-100 \%$ for aspergillosis (Brown et al. 2012; Verweij et al. 2016; Haidar and Singh 2018). The most common fungal nosocomial infections are those of endogenous origin, difficult to avoid, because they are caused by opportunistically pathogenic fungi being a part of the human microflora.

Current methods of preventing fungal infections remain unsatisfactory. Indeed, there are several antifungal compounds that are highly effective in some cases; however, they have limitations in use: nephrotoxicity and other adverse effects, drug interactions, and variability in absorption (Quindós et al. 2019). Clinically available antifungals used to treat invasive fungal infections represent four classes of drugs, whereas two of which, polyene macrolide antibiotics and synthetic azole derivatives target ergosterol, a component of the fungal cell membrane, either directly (the former) or its biosynthesis (the latter) (Van den Bossche et al. 1983; Gray et al. 2012). Other targets of established antifungal drugs include $\beta(1 \rightarrow 3)$ glucan synthase for echinocandins and RNA biosynthesis for 5-fluorocytosine. In addition, the frequent use of available fungistatic drugs, like Fluconazole, to prevent severe infections in immunocompromised patients, as part of supporting antibiotic therapy or in agriculture, promotes drug resistance, either specific or of the 
multidrug type (Azevedo et al. 2015). With this in mind, we should mention that right now, there are known cases of fungi resistant to all approved oral drugs (Wiederhold 2017) and the emerging fungal pathogen Candida auris is intrinsically resistant to the "golden standard" of antifungal chemotherapy, i.e. Amphotericin B. Depending on the place of research, the observed percentage of frequency of C. albicans strains resistant to Fluconazole ranges from less than 1 to 30-40 (Skrodenienè et al. 2006; Gualco et al. 2007; Jafari-Nodoushan et al. 2008). Similarly, azole-resistant $A$. fumigatus strains' prevalence reached $5 \%$ and $6 \%$ in the UK and Netherlands, respectively (Snelders et al. 2008; Howard et al. 2009), whereas in one Netherlands hospital, as much as $26 \%$ of Aspergillus strains were azole resistant (van Paassen et al. 2016). What is more, late diagnosis as well as the ability of fungal organisms to fast adaptation to a changing environment causes the treatment of mycoses to be excessively difficult and sustained. Therefore, there is an urgent need for the development of novel, highly selective drug candidates with a different mechanism of action for antifungal chemotherapy or for agricultural purposes. Fungal and mammalian cells are highly similar, therefore, to introduce a new antifungal drug, it is desirable to find molecular targets that will be absent in mammalian cells and simultaneously, crucial for the growth and virulence of fungal cells. For these reasons, enzymes unique for fungal cells, involved in amino acids biosynthesis pathways and protein biosynthesis may serve as a great source of molecular targets for novel potential drugs.

This review summarizes current knowledge on potential molecular targets for antifungal chemotherapy or agricultural applications, focusing on enzymes participating in the biosynthetic pathways of human-essential amino acids and involved in protein biosynthesis and post-translational modifications, such as elongation factors and aminoacyl-tRNA synthetases (aaRSa). Examples of numerous inhibitors of these enzymes exhibiting antifungal activity are presented.

\section{Molecular targets in fungal amino acid biosynthetic pathways}

Nine amino acids, namely: L-histidine, L-isoleucine, L-leucine, L-lysine, L-methionine, L-phenylalanine, L-threonine, L-tryptophan and L-valine are regarded as human essential, since there are no pathways of their biosynthesis from simple precursors in human cells. From this perspective, fungal enzymes involved in the pathways of human-essential amino acid biosynthesis might serve as an attractive source of novel molecular targets for antifungal chemotherapy. Yet it might seem questionable whether inhibition of human-essential amino acid biosynthesis would make a successful antifungal treatment, since amino acid requirements may be satisfied by the exogenous supply of amino acid and oligopeptide pool from human serum. From this point of view, the tryptophan and methionine pathways seem especially promising since human serum levels of these amino acids are particularly low enough to disable the rescue of amino acid concentrations caused by inhibition of its biosynthetic pathways in human pathogen cells (Han et al. 2018). Herein, we present the most interesting molecular targets in the fungal amino acid biosynthetic pathway and their potential inhibitors.

\section{Biosynthesis pathways of amino acids of the aspartate family}

Aspartate family refers to amino acids that are synthesized from L-aspartate through pathways absent in mammalian cells (Fig. 1).

Amino acids belonging to the aspartate family are: L-asparagine, L-aspartate, L-threonine, L-methionine, and L-isoleucine. The latter three are human-essential amino acids. Biosynthetic pathways of aspartate family amino acids involve common initial steps that convert oxaloacetate to L-aspartate and next to L-homoserine in three continuous steps. First, L-Aspartate under the action of aspartate kinase (Hom3p) is phosphorylated to L-4-aspartyl phosphate, that in the next step is converted into L-aspartate-4-semialdehyde and then to L-homoserine by aspartate semialdehyde dehydrogenase (Hom2p) and homoserine dehydrogenase (Hom6p). L-Homoserine is the branch point that can lead in two steps to the biosynthesis of either L-threonine and then to L-isoleucine or in several steps to L-methionine (methionine branch). These pathways involve several complex interactions that make them highly investigated in terms of a potential new antifungal target source (Ejim et al. 2004; Kingsbury et al. 2006; Kingsbury and McCusker 2010b).

One of the initial steps in the biosynthesis of aspartate family amino acids is catalyzed by aspartate semialdehyde dehydrogenase encoded by HOM 2 gene. It has been shown that deletion of the gene-encoding Hom $2 p$ causes a growth defect of bacteria (Galán et al. 1990; Harb and Kwaik 1998). As far as we know, the growth phenotype of fungal hom $2 \Delta$ mutants has not been studied, however, a recent study provided insights into Hom2p inhibitors derived from $p$-benzoquinone (Dahal and Viola 2018a). Especially one compound, 2-chloro-3-metoxy-1,4-naphtoquinone (Fig. 2, compound 1), was effective as an inhibitor of Hom $2 p$ in Cryptococcus neoformans, Candida albicans, Aspergillus fumigatus and Blastomyces dermatitidis, with $K_{i}$ values ranging from 0.88 to $2.5 \mu \mathrm{M}$. Another study determined the first cofactorbound and inhibitor-bound structures of aspartate semialdehyde dehydrogenase from the pathogenic fungi $B$. dermatitidis (Dahal and Viola 2018b). These structures revealed details of interactions between the enzyme and its inhibitor $p$-benzoquinone that provide insights into the design and 


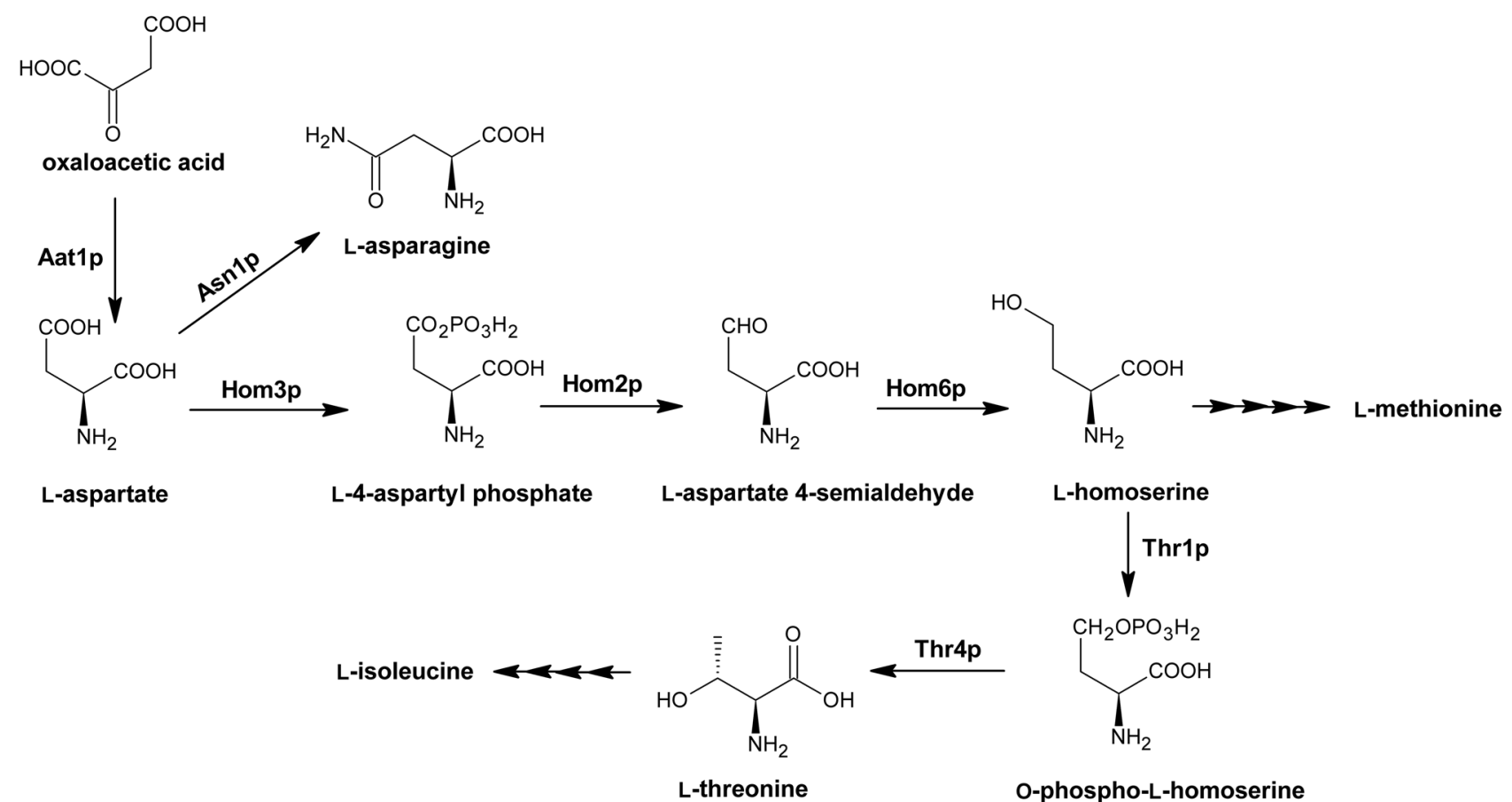

Fig. 1 Fungal aspartate family amino acid biosynthesis. Aat1p EC 2.6.1.1 aspartate transaminase; Asn1p EC 6.3.5.4 asparagine synthetase; Hom2p EC 1.2.1.11 aspartate semialdehyde dehydrogenase;
Hom3p EC 2.7.2.4 aspartate kinase; Hom6p EC 1.1.1.3 homoserine dehydrogenase; Thr1p EC 2.7.1.39 homoserine kinase; Thr4p EC 4.2.3.1 threonine synthase. Adapted from (Caspi et al. 2018)<smiles>COC1=C(Cl)C(=O)c2ccccc2C1=O</smiles>

2-Chloro-3-metoxy$1,4,-$ naphtoquinone<smiles>N[C@@H](CC(=O)CO)C(=O)O</smiles>

RI-331 (HONV)
3<smiles>Cc1cc(SCC([NH3+])C(=O)[O-])c2cc(Br)ccc2n1</smiles>

HS9<smiles>COc1ccc(C(=O)NN)c2ccccc12</smiles>

1-Carbohydrazinyl-4-methoxy1-naphthalene<smiles>N=C(N)NCCC[C@H](N)C(=O)N[C@@H](/C=C\CP(=O)(O)O)C(=O)O</smiles>

Rhizocticin A

Fig. 2 Inhibitors of fungal enzymes from the aspartate family pathway. Compound 1 2-Chloro-3-metoxy-1,4,-naphtoquinone; compound 2 RI-331 (HONV); compound 3 HS9; compound 4 1-Carbohydrazinyl-4-methoxy-1-naphtalene; compound 5 Rhiozocticin A

development of novel antifungal agents. It is worth mentioning that Viola et al. (2019) invented multiple phthalate derivatives potentially inhibiting aspartate Hom2p present in bacterial cells. The claimed compounds were various derivatives of 4-aminomethylphthalate, but only 3 of them were reported as potent inhibitors of aspartate semialdehyde dehydrogenase from Streptococcus pneumoniae.

The next step in the aspartate family amino acid biosynthesis pathway is catalyzed by the homoserine dehydrogenase Hom6p. There have been numerous study reports on the disruption of HOM6 gene in fungi; S. cerevisiae hom64 mutants exhibited growth inhibition due to accumulation of toxic aspartate $\beta$-semialdehyde and increased sensitivity to the immunosuppressant FK506 (Arévalo-Rodríguez et al. 2004). Disruption of the HOM6 gene in C. albicans caused decreased growth under amino acid starvation that could be rescued by addition of methionine or threonine. Additionally, HOM6 deletion resulted in decreased cell adhesion, probably because of threonine deficiency that likely leads to a reduction of mannoproteins levels, which are regarded significant for $C$. albicans adhesion and virulence (Kingsbury and McCusker 2008; Tsai et al. 2017). A well-known homoserine dehydrogenase inhibitor is the natural compound known as the antibiotic RI-331 or HONV ((S)-2-amino-4-oxo-5-hydroxypentanoic acid) (Fig. 2, compound 2). It was discovered in the $80 \mathrm{~s}$, but due to its 
antifungal properties, HONV derivatives are still being studied today. HONV was isolated from Streptomyces species and found to act as an enzyme-assisted suicide inhibitor of Hom6p, that is effective against $C$. albicans, $C$. tropicalis and $C$. glabrata but has no effect against Aspergillus species (Yamaguchi et al. 1988, 1992; Yamaki et al. 1990; Jacques et al. 2003). It was also proven that HONV can be useful in systematic murine candidiasis treatment in mice (Yamaguchi et al. 1988), however, its effectiveness under physiological conditions should be improved. One of the raised approaches was the eight dipeptides containing HONV as the C-terminal amino acid (Skwarecki et al. 2018). Constructed dipeptides were tested for anticandidal activity in different media. The results showed that HONV dipeptides demonstrated lower antifungal activity than HONV itself in minimal media, however, in RPMI-1640 medium that mimics the composition of low molecular weight compounds in human serum, five dipeptides (Ala-HONV, Ile-HONV, Leu-HONV, Nva-HONV, Val-HONV) demonstrated higher activity than RI-331, with MIC values of $64-128 \mu \mathrm{g} \mathrm{mL}^{-1}$. The HONV-containing oligopeptides seem possible to be further optimized towards enhanced antifungal activity. The more recent study involved a screen of a natural products database towards inhibitors of Hom6p of Paracoccidioides brasiliensis, one of the etiological agents of paracoccidioidomycosis (Bueno et al. 2019b). As a result, three molecules were found and tested in vitro, resulting in MIC values of 8,32 and $128 \mu \mathrm{g} \mathrm{mL}^{-1}$. Compound with the lowest MIC/ MFC values, HS9 (Fig. 2, compound 3), exhibited low cytotoxicity against human cell lines. HS9 is the most active antifungal compound among recently reported in the literature inhibitors of Paracoccidioides brasiliensis Hom6p. Summing up, HS9 may be considered as a promising lead compound for further development.

It was reported that $C$. albicans hom $6 \Delta$ cells were hypersensitive to hygromycin B, thus suggesting Hom6p involvement in protein glycosylation (Tsai et al. 2017), since previously a correlation between defects in protein glycosylation and hygromycin B sensitivity of $S$. cerevisiae was found (Dean 1995). Furthermore, it was revealed by proteomic studies that Hom6p is localized in both cytosolic and cell wall fractions of $C$. albicans (Ebanks et al. 2006; Montserrat Martínez-Gomariz et al. 2009; Tsai et al. 2017). Additionally, novel inhibitors of homoserine dehydrogenase were found among 4-methoxy-naphthalene derivatives (Bagatin et al. 2019). Among the several derivatives, one compound (Fig. 2, compound 4) with a carbohydrazide group attached in $\mathrm{C} 1$ of 4-methoxy-naphthalene ring was most active against Paracoccidioides spp. with MIC values ranging from 8 to $32 \mu \mathrm{g} \mathrm{mL}{ }^{-1}$. This compound also showed moderate antifungal activity against $C$. albicans, $C$. parapsilosis and C. glabrata $\left(128-256 \mu \mathrm{g} \mathrm{mL}^{-1}\right)$. What is more, this 4-methoxy-naphthalene derivative and amphotericin B combination resulted in a good synergistic antifungal effect against $P$. brasiliensis and simultaneously did not cause toxicity in monkey kidney and murine macrophage cells.

Conversion of L-homoserine to $\mathrm{L}$-threonine involves two steps catalyzed by homoserine kinase and threonine synthase encoded by THRI and THR4, respectively. Both of them could be regarded as potential molecular targets for antifungal chemotherapy. It was reported that both THRI and THR 4 genes are essential for growth and are required for virulence of $C$. albicans and $C$. neoformans cells (Kingsbury and McCusker 2008, 2010b). It was also suggested that the growth inhibition effect in THRI and THR4 mutants results from toxic homoserine accumulation in yeast cells (Kingsbury and McCusker 2010c). A more recent study revealed that $C$. albicans THRI depleted mutants exhibited increased sensitivity to oxidative and osmotic stress (Lee et al. 2018). Threonine synthase can be inhibited by a natural compound produced by Bacillus subtilis, known as Rhizocticin A (L-arginyl-L-2-amino-5-phosphono-3-cis-pentenoic acid, Fig. 2, compound 5), as reported by Kugler et al. (1990). Rhizocticin A successfully inhibited growth of S. cerevisiae, Schizosaccharomyces pombe and Yarrowia lipolytica with MIC values of $0.35 \mu \mathrm{g} \mathrm{mL}^{-1}$. No other inhibitors of fungal Thr $1 \mathrm{p}$ and Thr $4 \mathrm{p}$ have been reported so far.

\section{Methionine biosynthesis branch}

Every cell needs L-methionine to function properly, most of all, it is needed for protein biosynthesis as it plays a role of its initiator. L-Methionine is also involved in many metabolic processes and works as a precursor for the synthesis of $S$-adenosylomethionine (SAM), needed for the methylation reaction of DNA or phospholipids (Gophna et al. 2005). There are several reports of studies performed on fungal microorganisms confirming that enzymes involved in L-methionine biosynthesis pathway constitute a promising source of targets for new antifungal drugs (Aoki et al. 1995; Pascon et al. 2004).

The methionine branch of L-aspartate amino acid biosynthesis pathway exists in fungal, plant and bacterial cells and starts from L-homoserine, but subsequent reactions are not the same among these organisms (Gophna et al. 2005). In the first step of L-methionine biosynthesis (Fig. 3), in fungal cells, L-homoserine is $O$-acetylated upon the action of homoserine $O$-acetyltransferase (Met2p), however, in plant cells, L-homoserine is $O$-phosphorylated and bacterial cells produce $O$-succinyl-L-homoserine at this step. In the next stage, a sulfur atom is incorporated into the rising amino acid chain, either from inorganic sulfide via direct sulfhydrylation or from L-cysteine through the transsulfurylation pathway (Hébert et al. 2011; Kulikova et al. 2019). In the process of direct sulfhydrylation, $O$-acetyl-L-homoserine sulfhydrolase (Met17p) uses free sulfur atoms and $O$-acetyl-L-homoserine 


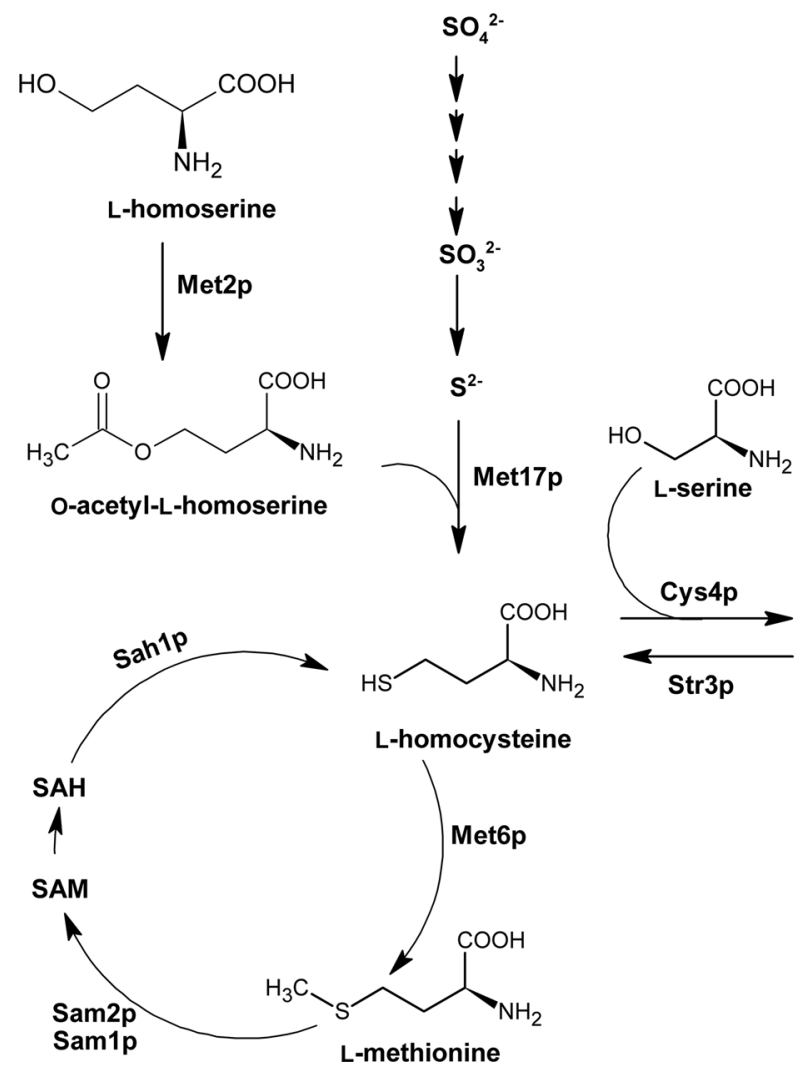

Fig. 3 Fungal L-methionine biosynthesis pathway. Cys3p EC 4.4.1.1 cystathionine- $\gamma$-lyase; Cys4p EC 4.2.1.22 cystathionine- $\beta$-synthase; Met2p EC 2.3.1.31 homoserine O-acetyltransferase; Met6p EC 2.1.1.13 methionine synthase; Met17p EC 2.5.1.49, EC 2.5.1.47 bifunctional $\mathrm{O}$-acetyl-L-homoserine $/ O$-acetyl-L-serine sulfhydro-

to produce L-homocysteine. Interestingly, in some fungal microorganisms, this step is catalyzed by bifunctional $O$-acetyl-L-homoserine/ $O$-acetyl-L-serine sulfhydrolase EC 2.5.1.49, EC 2.5.1.47 (Brzywczy and Paszewski 1993). Introduction of a sulfur atom through the transsulfurylation pathway requires the participation of two enzymes: cystathionine- $\gamma$-synthase (Str2p) and cystathionine- $\beta$-lyase (Str3p). Str2p utilizes $O$-acetyl-L-homoserine and L-cysteine to produce L-cystathionine, next reaction catalyzed by Str3p yields L-homocysteine. In many organisms, there also exists a reverse transsulfurylation pathway involving L-homocysteine transformation to L-cystathionine by cystathionine- $\beta$ synthase (Cys4p) and next its lysis back to L-cysteine upon the action of cystathionine- $\gamma$-lyase (Cys3p) (Hébert et al. 2011). The last step of L-methionine biosynthesis involves $S$-methylation of L-homocysteine catalyzed by methionine synthase (Met6p). It can be noted that L-cysteine biosynthesis is strictly related to L-methionine biosynthesis pathway. In some microorganisms, L-cysteine can be produced in two ways: through the reverse transsulfurylation pathway and via $O$-acetylserine pathway (Toh-e et al. 2018; de Melo et al. 2019).

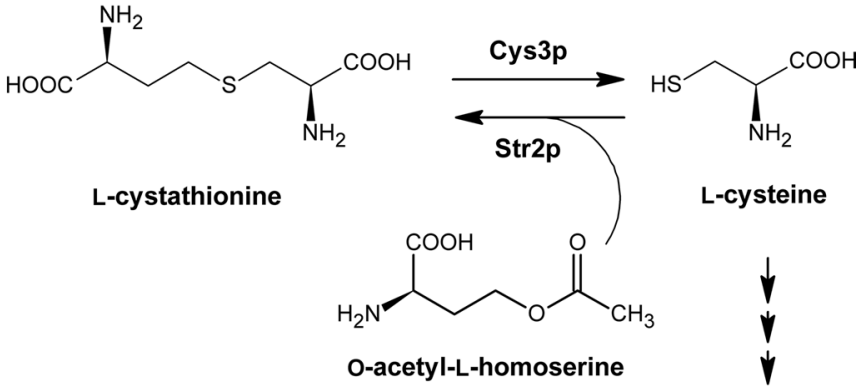

L-glutathione lase; Sah1p EC 3.3.1.1 adenosylhomocysteinase; Sam1p, Sam2p EC 2.5.1.6 methionine adenosyltransferase; Str2p EC/2.5.1.48 cystathionine- $\gamma$-synthase; Str3p EC 4.4.1.8 cystathionine- $\beta$-lyase. Adapted from (Caspi et al. 2018)

The first enzyme of the L-methionine biosynthesis pathway, homoserine $O$-acetyltransferase (Met2p), is undoubtedly a promising target for novel antifungal agents, since it was found that as required for virulence of $C$. neoformans in a mouse inhalation model (Nazi et al. 2007). Several other studies performed on C. albicans, $C$. guilliermondii and $S$. cerevisiae showed that MET2 gene-depleted mutant cells are methionine auxotrophs (Singh and Sherman 1974; Kingsbury and McCusker 2010c; Obando Montoya et al. 2014). Nazi et al. (2007) discovered an effective inhibitor of Met2p, however, it was unsuccessful against $C$. neoformans in minimal medium. Since then, few inhibitors of Met2p have been discovered. A study stating high structural similarity between homoserine $O$-transacetylases from different bacterial and fungal species also suggested that the enzyme active site is highly druggable (Chaton et al. 2019). Serine$O$-acetyltransferase EC 2.3.1.30 (Cys2p) catalyzes similar reaction to that catalyzed by Met2p, but Cys2p uses L-serine as a substrate to produce $O$-acetyl-L-serine instead of $O$-acetyl-L-homoserine. Chen et al. (2019a) found six compounds inhibiting serine- $O$-acetyltransferase from Staphylococcus aureus $\left(\mathrm{IC}_{50}\right.$ ranging from 29.83 to $203.13 \mu \mathrm{M}$ ). 
Two of those, i.e. 11-oxo-ebracteolatanolide B and (4R,4aR)-dihydroxy-3-hydroxymethyl-7,7,10a-trimethyl2,4,4a,5,6,6a,7,8,9,10,10a,10b-dodecahydrophenanthro[3,2-b] furan-2-one also exhibited antibacterial activity against MRSA with MIC values of $12.5 \mu \mathrm{g} \mathrm{mL}^{-1}$ and $25 \mu \mathrm{g} \mathrm{mL}^{-1}$. In another study, a virtual screening of ChemDiv libraries was conducted to identify potential inhibitors of serine$O$-acetyltransferase (Magalhães et al. 2020). Out of the 73 evaluated compounds, 6 displayed an inhibitory effect with $\mathrm{IC}_{50}$ below $100 \mu \mathrm{M}$, but only 1 inhibited the growth of $E$. coli in $20 \% \mathrm{LB}$ medium (MIC $64 \mu \mathrm{g} \mathrm{mL}^{-1}$ ). Conclusions resulting from studies on serine- $O$-acetyltransferase inhibitors may be exploited in the rational design of compounds targeting homoserine $O$-acetyltransferase.

Another subsequent enzyme involved in L-methionine biosynthesis pathway is the bifunctional $O$-acetyl-Lhomoserine $/ O$-acetyl-L-serine sulfhydrolase encoded by MET17 gene (also named MET15 and MET25). It was shown that $S$. cerevisiae and $C$. glabrata mutants deficient in $O$-acetyl-L-homoserine sulfhydrolase activity were methionine or sulfur auxotrophs (Singh and Sherman 1974; Yadav et al. 2011). These results indicate that $S$. cerevisiae and $C$. glabrata only possess a transsulfurylation pathway allowing for L-cysteine production (Hébert et al. 2011). In addition, it was shown that $S$. cerevisiae cells lacking Met17p activity were more sensitive to sulfometuron methyl agent causing starvation for isoleucine and valine (Bae et al. 2017). Studies performed on $C$. guilliermondii mutant depleted in Met17p encoding gene, revealed its prototrophic character even in the absence of methionine (Obando Montoya et al. 2014). Prototrophic character was also observed while disruption of $O$-acetyl-L-homoserine/ $O$-acetyl-L-serine sulfhydrolase encoding gene in $C$. albicans cells, however, it led to a severe defect of growth on sulfate (Viaene et al. 2000). As far as we know, there are no reports of fungal $O$-acetyl-L-homoserine/ $O$-acetyl-L-serine sulfhydrolase inhibitors, but there are several examples of inhibitors of the bacterial enzyme (Joshi et al. 2019). The most potent one is 3-((Z)-((Z)-5-(4-fluorobenzylidene)-3-methyl-4-oxothiazolidin-2-ylidene)amino)benzoic acid, with $\mathrm{IC}_{50}$ value of $19 \mathrm{nM}$ (Poyraz et al. 2013).

Methionine synthase is encoded by the MET6 gene and catalyzes the last step of L-methionine biosynthesis pathway. This enzyme also exists in mammalian cells, but it is structurally different from the fungal version (Ubhi et al. 2014). Mammalian methionine synthase uses cobalamin as a cofactor, while the fungal enzyme is cobalamin independent, resulting in mechanistic differences between both enzyme versions. What is more, inhibition of methionine synthase results in the accumulation of toxic intermediates involved in L-methionine biosynthesis pathway: L-homoserine and L-homocysteine, the former also causes the disruption of ergosterol biosynthesis (Pascon et al. 2004; Kingsbury and
McCusker 2010a,b,c). The above reasons raise the possibility that fungal Met6p could be a promising target for the development of novel antifungal drugs. Studies performed with $C$. albicans double deletion mutants of MET6 gene revealed that Met6p is essential for fungal growth and full virulence in a mouse infection model (Aoki et al. 1995; Suliman et al. 2007). In filamentous fungi, Aspergillus fumigatus methionine synthase gene is essential in vivo and required for the invasion of the host cell (Amich et al. 2016). More recent study revealed that Pichia pastoris MET6 deleted cells were auxotrophic for methionine and adenine, thus indicating that methionine synthase is required for the biosynthesis of both methionine and adenine. Interestingly, this study also showed that Met6p is localized in the nucleus of $P$. pastoris and $C$. albicans cells, but in the cytoplasm of $S$. cerevisiae cells. It was suggested that nuclear localization of Met6p is a unique feature of respiratory yeasts such as $P$. pastoris and $C$. albicans and is essential for the stability and function of the enzyme (Sahu et al. 2017). Surprisingly, up to this date, no successful inhibitors of methionine synthase demonstrating antifungal effect have been reported. Recently, nine bafilomycin compounds were isolated from the fermentation broth of Streptomyces albolongus (Ding et al. 2016). Among them, three new compounds were active against $C$. parapsilosis with MIC value $1.56-3.13 \mu \mathrm{g} \mathrm{mL}^{-1}$, but one compound bafilomycin $\mathrm{C} 1$ (Fig. 4, compound 1), known before as a good antibacterial agent, displayed an antifungal effect towards $C$. albicans, $C$. parapsilosis and C. neoformans with MIC of $1.56 \mu \mathrm{g} \mathrm{mL}^{-1}$. Later, it was discovered that bafilomycin $\mathrm{C} 1$ caused a significant downregulation of the expression of ergosterol biosynthesis-related genes in $C$. albicans. Moreover, the expression of methionine synthase encoding gene was also downregulated by 2.7fold (Su et al. 2018). Met6p is certainly an attractive target for novel antifungal therapies, however, successful inhibitors of methionine synthase still need to be found.

Transsulfurylation pathway utilizes L-cysteine to produce L-homocysteine and involves two enzymes: cystathionine$\gamma$-synthase and cystathionine- $\beta$-lyase encoded by STR 2 and STR3 genes, respectively. In the first step of the transsulfurylation pathway, Str2p uses cysteine and $O$-acetyl-L-homoserine as substrates to produce L-cystathionine, that is transformed in the subsequent reaction to L-homocysteine upon the action of Str3p. S. cerevisiae cells depleted in STR2 and STR3 genes were unable to grow in a medium containing glutathione as the only sulfur source, and in the case of $S$. cerevisiae str $3 \Delta$ mutant in a medium containing cystathionine as the sole sulfur source (Hansen and Johannesen 2000). Excess cysteine level can induce a toxic effect, thus its metabolism is important (Kumar et al. 2006). However, a recent study reported that $S$. cerevisiae str $2 \Delta$ cells unable to use cysteine, did not exhibit significant enhancement of sensitivity to cysteine toxicity, indicating that cysteine is 
1

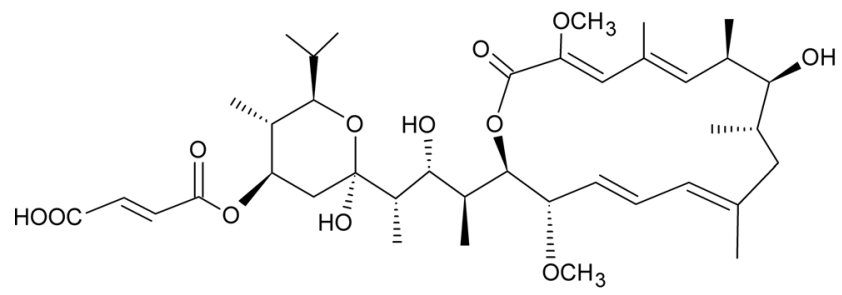

Bafilomycin C1
2

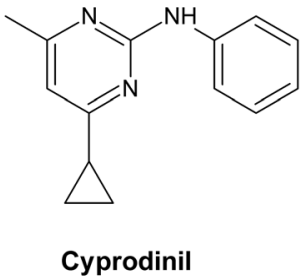

3

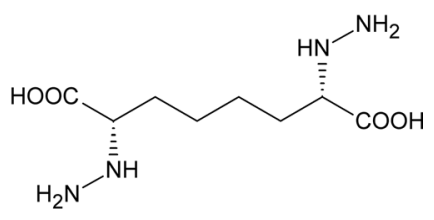

(L,L)-2,7-Bis-(hydrazino)-1,8octanedioic acid

Fig. 4 Inhibitors of fungal enzymes from the L-methionine biosynthesis pathway. Compound 1 Bafilomycin C1; compound 2 Cyprodinil; compound 3 (L,L)-2,7,-Bis-(hydrazino)-1,8-octanedioic acid

not found as a toxic metabolite in yeast cells (Deshpande et al. 2017). On the other hand, cystathionine- $\gamma$-synthase was proven to play an important role in regulating various processes in Botrytis cinerea cells (Shao et al. 2016). It was shown that $B$. cinerea cells deprived of STR 2 gene could not grow in a minimal medium, suggesting that $S t r 2 p$ is required for vegetative differentiation of the cells. Deletion mutants exhibited decreased conidation and increased sensitivity to osmotic, oxidative, and thermal stresses. Most importantly, it was shown that $\operatorname{str} 2 \Delta$ mutants were avirulent on host plant tissue. These results suggest that Str2p takes part in multiple regulatory functions in $B$. cinerea. Since mammalian cells lack the transsulfurylation pathway, Str2p and Str3p should be considered as a potential target for novel antifungal agents. Sagong et al. (Sagong and Kim 2017) determined the crystal structure of cystathionine- $\gamma$-synthase from Corynebacterium glutamicum complex with its inhibitor DL-(E)-2-amino-5-phosphono-3-pentenoic acid (APPA), but its antifungal activity still needs to be investigated. In a recent study, anilinopyrimidine fungicide derivative Cyprodinil (4-cyclopropyl-6-methyl- $N$-phenylpyrimidin-2-amine) (Fig. 4, compound 2) was investigated as a potential inhibitor of enzymes involved in L-methionine biosynthesis pathway (Hou et al. 2018). The results showed that Cyprodinil exhibited strong fungicidal activity against Sclerotinia sclerotiorum cells in vitro, but it targeted neither cystathionine$\gamma$-synthase (MetB) nor cystathionine- $\beta$-lyase (MetC), since the sequence alignment showed that there was no alteration of amino acid in MetB and MetC between cyprodinil-resistant mutants and their sensitive parental strains. There have been few reports of inhibitors targeting enzymes involved in the reverse transsulfurylation pathway: cystathionine$\beta$-synthase (Cys4p) and cystathionine- $\gamma$-lyase (Cys3p). A crystal structure of $S$. cerevisiae Cys $4 p$ was presented and (L,L)-2,7-bis(hydrazino)-1,8-octanedioic acid (Fig. 4, compound 3) has been proposed as its potential inhibitor (Tu et al. 2018). It must be noted that this enzyme-inhibitor modelling study was conducted to bring insights into the development of a therapeutic agent for stroke treatment.
In fact, this octanedioic acid derivative has been shown to inhibit purified cystathionine- $\beta$-synthase in an animal neuroblastoma model (McCune et al. 2016).

\section{Branched-chain amino acids biosynthesis}

L-Leucine, L-valine and L-isoleucine are amino acids that contain a branched side chain in their structures. These amino acids are essential for humans, because human cells, unlike fungi, are unable of their biosynthesis. This makes enzymes of the branched-chain amino acid fungal pathways as potential targets for antifungal chemotherapy. L-Isoleucine biosynthesis derives from the aspartate pathway and it is parallel with L-valine biosynthesis pathway, since both are catalyzed by the same enzymes, but the intermediates are different (Fig. 5).

L-Isoleucine biosynthetic pathway starts from utilizing L-threonine as a precursor and its conversion into 2-oxobutanoate by the enzyme threonine ammonia-lyase (Ilv1p). In the next step, acetolactate synthase composed of two subunits encoded by ILV2 and ILV6 genes, combines pyruvate and 2-oxobutanoate to yield (2S)-2-ethyl-2-hydroxy-3-oxobutanoate. Next reaction is catalysed by ketol-acid reductoisomerase (NADP $(+)$ ) encoded by ILV5 gene, generating (2R,3R)-2,3-dihydroxy-3-methylpentanoate. Subsequently, dihydroxyacid dehydratase (Ilv3p) catalyses the dehydration reaction producing 3-methyl-2-oxobutanoate. Finally, in the last step, branched-chain amino acid transaminase (Bat1p, Bat $2 p)$ catalyses the synthesis of L-isoleucine or L-valine. 3-Methyl-2-oxobutanoate, a product of dihydroxyacid dehydratase (Ilv3p) reaction, is a branching point leading either to L-leucine or L-valine biosynthesis. The first committed step of L-leucine biosynthesis is catalyzed by 2-isopropylmalate synthase (Leu4p) utilizing acetyl coenzyme A and 3-methyl-2-oxobutanoate to produce (2S)-2-isopropylmalate. This reaction occurs in mitochondria, from which (2S)-2-isopropylmalate is transported to the cytosol via the oxaloacetate/sulfate carrier Oac1p (López et al. 2015). Two subsequent reactions occur in the cytoplasm and involve 


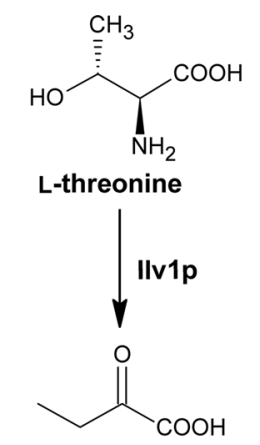

\footnotetext{
2-oxobutanoate
}

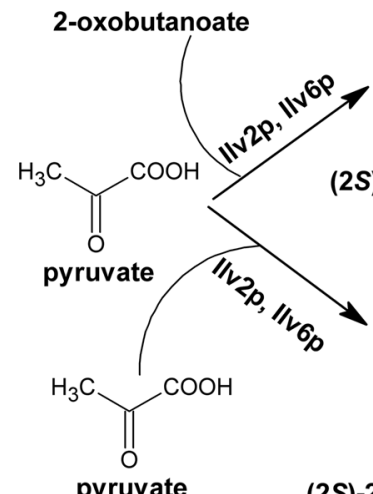

(2S)-2-ethyl-2-hydroxy3-oxobutanoate<smiles>C1C[Pb]2CC1C2</smiles><smiles>CC[C@@](C)(O)[C@H](O)C(=O)O</smiles><smiles>C1CC[AsH2+]C1</smiles>

$(2 R, 3 R)-2,3-$ dihydroxy3-methylpentanoate

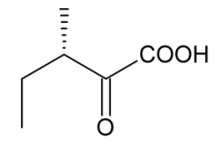

(3S)-3-methyl2-oxopentanoate

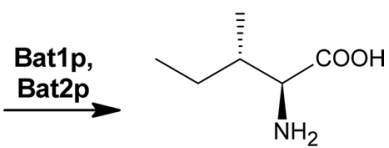

L-isoleucine

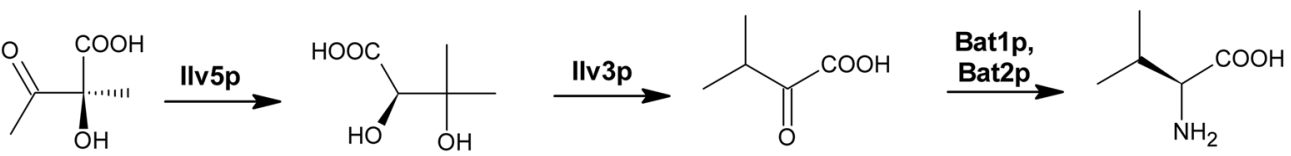

(2S)-2-hydroxy-2-methyl3-oxobutanoate

(2R)-2,3-dihydroxy3-methylbutanoate

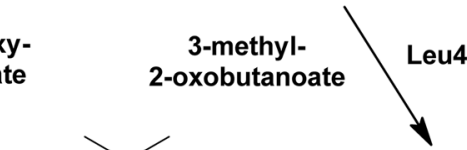

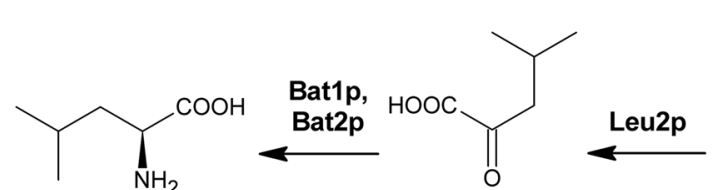

4-methyl2-oxopentanoate
L-leucine

(2R,3S)-3-isopropylmalate

L-valine
Fig. 5 Fungal branched-chain amino acid pathway. Bat1p, Bat2p EC 2.6.1.42 branched-chain amino acid transaminase; Ilv1p EC 4.3.1.19 threonine ammonia-lyase; Ilv2p, Ilv6p EC 2.2.1.6 acetolactate synthase; Ilv3p EC 4.2.1.9 dihydroxyacid dehydratase; Ilv5p EC 1.1.1.86

3-isopropylmalate dehydratase (Leu1p) and 3-isopropylmalate dehydrogenase (Leu2p), to catalyze reactions that yield (2R,3S)-3-isopropylmalate and 4-methyl-2-oxopentanoate, respectively. The last step is the branched-chain amino acid transaminase (Bat1p, Bat2p) catalyzed reaction to produce L-leucine (Kohlhaw 2003).

Even though inhibition of L-threonine biosynthesis would simultaneously prevent L-isoleucine biosynthesis, enzymes involved in this pathway are regarded as a potential source of antifungal targets. First, C. albicans, C. neoformans, and $S$. cerevisiae ilv $2 \Delta$ or ilv $1 \Delta$ mutants displayed attenuated virulence in a murine model of infection and revealed a significant loss of viability under isoleucine and valine starvation (Kingsbury et al. 2004, 2006; Pascon et al. 2004; Kingsbury and McCusker 2010a). Moreover, ILV2 and ILV6 genes of Fusarium graminearum are essential for amino acid biosynthesis, since disruption mutants of both ketol-acid reductoisomerase (NADP(+)); Leu1p EC 4.2.1.33 3-isopropylmalate dehydratase; Leu2p EC 1.1.1.85 3-isopropylmalate dehydrogenase; Leu4p EC 2.3.3.13 2-isopropylmalate synthase. On the base of (Caspi et al. 2018)

catalytic and regulatory subunits of acetolactate synthase were auxotrophic towards branched-chain amino acids (Liu et al. 2015). Recently, it was discovered that host-induced ILV2 or ILV6 gene silencing of one of the most destructive cotton plant fungal pathogen Verticillium dahlia, resulted in a dramatic reduction in pathogenicity (Wei et al. 2020).

Until now, several fungal acetolactate synthase inhibitors have been discovered among commercial herbicides belonging to the sulfonylureas family. Especially two well-known herbicides: chlorimuron ethyl and ethoxysulfuron (Fig. 6, compounds 1-2) were reported as potent $C$. albicans acetolactate synthase inhibitors, with $\mathrm{MIC}_{50}$ value of $2 \mu \mathrm{M}$ (Lee et al. 2013).

A series of sulfonylurea derivatives containing an alkenyl moiety have been synthesized and said to be putative inhibitors of fungal Ilv2p/Ilv6p, wherein one compound (Fig. 6, compound 3 ) was distinguished to be an active antifungal 


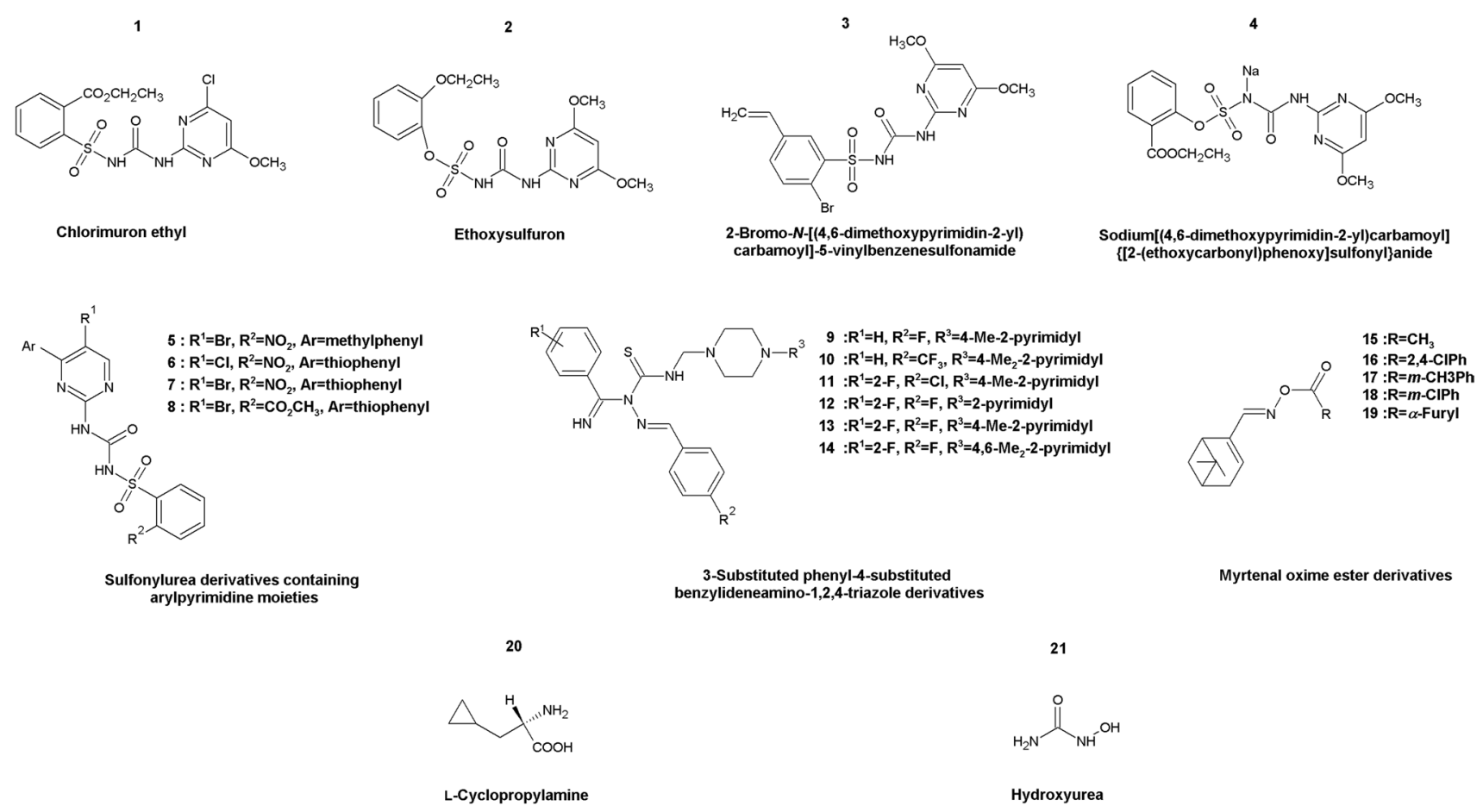

Fig. 6 Inhibitors of fungal enzymes from the branched-chain amino acids biosynthesis pathway. Compound 1 Chlorimuron ethyl; compound 2 Ethoxysulfuron; compound 3 2-Bromo- $N$-[(4,6-dimethoxypyrimidin-2-yl)carbamoyl]-5-vinylbenzensulfoamide; compound 4 Sodium[(4,6-dimethoxypyrimidin-2-yl)carbamoyl]\{[2-(ethoxy-

with $\sim 90 \%$ in vitro inhibitory rate at $50 \mu \mathrm{g} \mathrm{mL}^{-1}$ dosage in mycelium growth rate method (similarly potent as model compound, chlorothalonil against plant pathogens Ceratobasidium cornigerum and Sclerotinia sclerotiorum) (Wei et al. 2016). In another study, Garcia et al. (Garcia et al. 2018) discovered that chlorimuron ethyl (Fig. 6, compound 1) displayed a broad-spectrum antifungal activity against C. albicans, C. parapsilosis, C. glabrata and S. cerevisiae, with MIC values of $0.03 \mu \mathrm{g} \mathrm{mL}^{-1}, 0.003 \mu \mathrm{g} \mathrm{mL} \mathrm{L}^{-1}$, $0.005 \mu \mathrm{g} \mathrm{mL}^{-1}$, and $0.008 \mu \mathrm{g} \mathrm{mL}^{-1}$, respectively. Antifungal activity of chlorimuron ethyl could be suppressed by supplementation with a combination of isoleucine and valine, but this effect could be abolished upon addition of leucine, proline, or ammonium sulfate. Chlorimuron ethyl turned out to be highly effective in reducing the overall mortality rates of $C$. albicans infected mice by clearing pathogenic fungal burdening of lungs, liver and spleen. In a recent study, 5 novel acetolactate synthase inhibitors have been discovered among 68 derivatives of ethoxysulfuron that displayed increased inhibition of Ilv2p/Ilv6p (Wu et al. 2019). Compound (Fig. 6, compound 4) exhibiting the utmost inhibition constant $\left(K_{i} 6.7 \mathrm{nM}\right)$ was also the most effective antifungal agent against $C$. albicans, $C$. parapsilosis and $S$. cerevisiae with MIC values of $1.25 \mu \mathrm{g} \mathrm{mL}^{-1}, 1.25 \mu \mathrm{g} \mathrm{mL}^{-1}$ and $2.5 \mu \mathrm{g} \mathrm{mL}{ }^{-1}$, respectively. This compound showed activity carbonyl)phenoxy]sulfonyl \}anide; compounds $\quad 5-8 \quad$ Sulfonylurea derivatives containing arylpyrimidine moieties; compounds 9-14 3-Substituted phenyl-4-substituted benzylideneamino-1,2,4-triazole derivatives; compounds 15-19 Myrtenal oxime ester derivatives; compound 20 L-Cyclopropylamine; compound 21 Hydroxyurea

in the nematode model, suggesting that it could be considered as a candidate for further research. Several novel sulfonylurea inhibitors of acetolactate synthase containing arylpyrimidine moieties have been designed and evaluated for fungicidal activity. Four derivatives (Fig. 6, compounds 5-8) showed broad-spectrum and antifungal activity against Fusarium omysporum, Cercospora arachidicola, Physalospora piricola, Gibberella zeae, Fusarium moniliforme, Sclerotinia sclerotiorum, Corticium gramineum, Helminthosporium maydis, Phytophthora infestans, Rhizoctonia solani and showed $29-98 \%$ in vitro inhibitory rate at $50 \mu \mathrm{g} \mathrm{mL}^{-1}$ concentration (mycelium growth rate method) (Chen et al. 2019b). Above all, these compounds exhibit low toxicity in mammals; therefore, serve as an appealing novel class of antifungals that needs to be further optimized (Garcia et al. 2018).

Ketol-acid reductoisomerase (NADP $(+)$ ) is encoded by ILV5 gene, and turned out to be non-essential for virulence in a murine fungal infection model of $C$. albicans (Becker et al. 2010), nevertheless, there are reports of several inhibitors of this enzyme. First, Wang et al. (Wang et al. 2017) synthesized a series of 3-substituted phenyl-4-substituted benzylideneamino-1,2,4-triazole Mannich bases and bisMannich bases that displayed notable activities against Cercospora arachidicola, Physalospora piricola and 
Rhizoctonia cerealis at the concentration of $50 \mu \mathrm{g} \mathrm{mL} \mathrm{L}^{-1}$. Especially, several lead compounds (Fig. 6, compounds 9-13) appeared fungicidal towards $P$. piricola in the mycelium growth rate test. Interestingly, only one compound (Fig. 6, compound 14) that exhibited potent in vitro inhibitory activity against Ilv5p enzyme with $\mathrm{K}_{\mathrm{i}}$ value of $0.38 \mu \mathrm{mol} \mathrm{L}-1$, displayed a moderate fungicidal activity of $13.6 \%, 69.6 \%$ and $51.4 \%$ against $C$. arachidicola, P. piricola and $R$. cerealis, respectively. In another study, compounds targeting ketol-acid reductoisomerase (NADP $(+))$ were designed and synthesized from a natural forest product $\alpha$-pinene (Lin et al. 2019); resulting in 18 myrtenal oxime ester compounds that were tested for in vitro antifungal potential towards Fusarium oxysporum, Fusarium cucumerinum, $P$. piricola, C. arachidicola, Alternaria solani, and Gibberella zeae. Several compounds (Fig. 6, compounds 15-19) showed good antifungal activity against all tested fungi at the concentration of $50 \mu \mathrm{g} \mathrm{mL}^{-1}$ in the agar dilution method; however, the best results were obtained for $P$. piricola with a relative inhibitory rate ranging from 53 to $81 \%$. Recently, the X-ray structure of bacterial ketol-acid reductoisomerase (NADP $(+))$ from Staphylococcus aureus was investigated to model its reaction mechanism and interaction with substrates and inhibitors. In this study, a potential inhibitor, 2-carboxylate-lactic acid, was specially designed based on the indications resulting from the enzyme mechanism. Additionally, two substrate analogues, 2-trihalomethyl acetolactic acid, and 2-glutaryl lactic acid were discovered. The described mechanism-inspired strategy design of enzyme inhibitors could be useful for the exploration of novel antifungal agents (Yu et al. 2020).

Subsequent enzyme in L-isoleucine biosynthesis pathway is dihydroxyacid dehydratase encoded by $I L V 3$. This enzyme catalyzes the dehydration reaction producing $\alpha$-ketoacids, 3-methyl-2-oxobutanoate and (3S)-3-methyl-2-oxopentanoate. A recent study demonstrated that deletion of ILV3 gene of Fusarium graminearum, a human pathogenic fungus, is crucial for the biosynthesis of branched-chain amino acids (Liu et al. 2019). Fgilv3s mutants could not grow on amino acid depleted medium; however, supplementation of exogenous isoleucine or valine rescued the auxotrophy. ILV3 depleted strains also exhibited reduced virulence, thus indicating that Ilv3p could be an interesting potential antifungal target. It is worth mentioning that product of the reaction catalyzed by dihydroxyacid dehydratase, 3-methyl-2-oxobutanoate, is also involved in pantothenate production, a subsequent precursor of CoA (Meir and Osherov 2018). As far as we know, there are not many successful inhibitors of Ilv3p, however, Yan et al. (2018) discovered that the fungal sesquiterpenoid aspterric acid is an inhibitor of Ilv3p that could be used as a potential herbicide.

The first enzyme of L-leucine biosynthesis pathway, 2-isopropylmalate synthase, is encoded by LEU4 gene. This enzyme is highly conserved and can be inhibited by leucine via feedback inhibition mechanism (Kohlhaw 2003). It is noteworthy that $(2 S)$-2-isopropylmalate formed upon the action of Leu4p, plays a dual role in the cell. It acts as an intermediate for L-leucine biosynthesis and as a coactivator of the Leu3p master regulator. The regulatory protein, Leu3p, modulates the expression of several genes within and beyond amino acid metabolism and senses 2-isopropylmalate concentrations. At high 2-isopropylmalate concentrations, Leu3p acts as an activator of transcription, while at low concentrations, it acts as a repressor (Kohlhaw 2003). In a recent study, Orasch et al. (2019) proved that in A. fumigatus deprivation of 3-isopropylmalate dehydratase or 2-isopropylmalate synthase encoding genes (A. fumigatus equivalents, $L E U A$ and $L E U C$, respectively) results in leucine auxotrophy, that could be cured by exogenous leucine supplementation, with a note that leuCA mutant required significantly higher supplementation. It was also discovered that lack of LeuAp or LeuCp activity attenuates the virulence of A. fumigatus in the Galleria mellonella larvae infection model. While all wild-type infected larvae died on

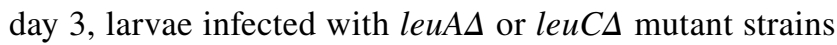
stayed alive until the end of the experiment (6 days) with survival rates of $60 \%$ and $80 \%$, respectively. It was shown that leuCs mutant was completely avirulent in a mouse infection model. Taken together, this study proved that L-leucine biosynthesis is crucial for the growth and virulence of A. fumigatus. 2-Isopropylmalate synthase can also exist in the form of two isoenzymes encoded by LEU4 and LEU9 genes, as reported in S. cerevisiae (Kohlhaw 2003). It was discovered that LEU4 and LEU9 S. cerevisiae double deletion mutants were absolute leucine auxotrophs in glucose or ethanol containing medium (López et al. 2015). Interestingly, the single leu $9 \Delta$ mutant exhibited wild-type phenotype on glucose or ethanol containing medium as a sole carbon source, whereas the leu $4 \Delta$ mutant was a partial auxotroph (López et al. 2015). Above studies show that 2-isopropylmalate synthase is worth further investigation as a potential molecular target for novel antifungals.

L-Cyclopropylalanine (Fig. 6, compound 20) is a natural compound produced by the mushroom Amanita virgineoides and exhibits a significant antifungal effect towards 12 fungal species; the most sensitive were Ascochyta gossypii, Colletotrichum gloeosporioides and Fusarium graminearum (Ma et al. 2017). It was discovered that the addition of leucine, but not any other amino acid, markedly decreased antifungal effect, suggesting that L-cyclopropylalanine inhibits L-leucine biosynthesis pathway. In fact, L-cyclopropylalanine inhibited 2-isopropylmalate synthase purified from $M$. tuberculosis, at the same rate as it was inhibited by leucine. An antifungal effect of L-cyclopropylalanine was tested against $C$. albicans, S. cerevisiae, and E. coli; the result showed that 
L-cyclopropylalanine had a strong antifungal effect with MIC values of $19.2 \mu \mathrm{M}$ and $44.5 \mu \mathrm{M}$ towards $C$. albicans and S. cerevisiae, respectively. It is important to add that L-cyclopropylalanine shows little (if any) toxicity in rats, thus showing that selectivity towards fungal cells is another of its assets. Taken together, L-cyclopropylalanine should be considered as a lead compound for the future development of novel antifungal agents.

3-Isopropylmalate dehydratase encoded by the LEUI gene catalyzes the conversion of (2S)-2-isopropylmalate into (2R,3S)-3-isopropylmalate. In a study performed on $C$. neoformans, LEU1 gene deletion cells could not grow in a medium lacking leucine, with ammonium sulfate as a sole nitrogen source, thus confirming that Leu1p is essential for L-leucine biosynthesis (Do et al. 2016). Interestingly, the addition of leucine to the medium containing glutamine or asparagine as the sole nitrogen source restored the growth of LEU1 mutant cells. This phenomenon was probably due to the nitrogen catabolite repression that interfered with leucine uptake in the presence of ammonium sulfate as a nitrogen source. Further studies revealed that mutant cells depleted in LEU1 gene possessed dysfunctional mitochondria and were hypersensitive to oxidative stress and cell wall perturbation agents. Most importantly, leul$\Delta$ mutants appeared to be attenuated in virulence in a mouse infection model. A more recent study was conducted on LEUI-deficient strains of Magnaporthe oryzae rice blast fungus (Tang et al. 2019), where deletion of $L E U 1$ gene also led to leucine auxotrophy that could be rescued by exogenous supplementation of leucine or rice leaf extract. This study also revealed a critical contribution of Leu1p in the pathogenesis, vegetative growth, and asexual development of $M$. oryzae. Results of these studies suggest Leu1p may be a potential target for novel antifungal drugs. Surprisingly, a commonly known drug, hydroxyurea (Fig. 6, compound 21), was found to (potentially) affect 3-isopropylmalate dehydratase. Hydroxyurea has an antiproliferative activity that is widely used in the treatment of chronic myeloid leukemia, sickle cell disease, and AIDS. Moreover, it was proven to alter iron-sulfur centers $(\mathrm{Fe}-\mathrm{S})$ in vivo via mechanism incorporating the production of reactive oxygen species (ROS) (Huang et al. 2016). Fe-S are metallic cofactors associated with proteins that allow fine redox tuning, and Leu $1 p$ happens to contain one. The study revealed hydroxyurea altered Leu1p Fe-S centers in S. cerevisiae cells, but not in the purified enzyme. Up to $3 \mathrm{~h}$ exposure of the wild-type yeast strains to hydroxyurea resulted in a three to fourfold decrease in Leu $1 p$ activity. However, hydroxyurea did not alter semi-purified Leu1p activity, even at higher concentrations. This suggests that the deleterious effect of hydroxyurea on $\mathrm{Fe}-\mathrm{S}$ centers might be due to cell metabolism (Huang et al. 2016). Nevertheless, this interesting aspect of altering Leu1p activity requires further studies.

\section{Biosynthesis of aromatic amino acids}

Bacteria, plants, and fungi synthesize aromatic amino acids, that is, L-phenylalanine, L-tyrosine, and L-tryptophan, throughout the so-called shikimate pathway, because shikimate serves as a major intermediate (Mir et al. 2015). In contrast, mammals must acquire L-Phe and L-Trp from their diet (the enzyme converting L-Phe into L-Tyr is present in mammals), since they are essential for primary metabolism. The shikimate pathway converts D-erythrose-4-phosphate and phosphophenylopyruvate to D-chorismate in seven enzymatic steps catalyzed by: 3-deoxy-7-phosphoheptulonate synthase (Aro3p/Aro4p), pentafunctional AROM polypeptide (Aro1p) and chorismate synthase (Aro2p) (Braus 1991) (Fig. 7). D-Chorismate serves as a last common precursor for the synthesis of a variety of aromatic compounds, including aromatic amino acids. Enzyme chorismate mutase (Aro7p) converts D-chorismate to prephenate, an intermediate for L-tyrosine and L-phenylalanine biosynthesis. However, the intermediate for L-tryptophan biosynthesis is anthranilate, produced from D-chorismate by anthranilate synthase (Trp2p). The aromatic amino acid biosynthesis pathway has been intensively studied in plants and bacteria, yet it has been proven that bacteria lacking any gene involved in the shikimate pathway cannot survive in vivo (Mir et al. 2015). Unfortunately, the fungal biosynthetic pathway of aromatic amino acids is poorly categorized. Nevertheless, enzymes of the shikimate pathway serve as an attractive source of molecular targets for the design of novel antifungal drugs. In fact, there are already several reports on the vital role of fungal enzymes involved in the biosynthesis of aromatic amino acids (Sousa et al. 2002; Brunke et al. 2010).

One of the first enzymes appearing in the fungal aromatic amino acid biosynthesis pathway is the pentafunctional AROM polypeptide encoded by AROI gene. This enzyme is particularly interesting because of its complex, multi-domain structure that allows catalyzing five consecutive steps of the shikimate pathway (Duncan et al. 1988). There are not many reports on fungal Arolp investigation, however, via the doxycycline-repressible expression system, the $A R O 1$ gene was defined as essential for $C$. albicans (O'Meara et al. 2015). Recently, Yeh et al. (2018) provided new insights. In this study, C. albicans tetracycline-regulated (TR) knockdown strains depleted in ARO1 gene displayed decreased growth without aromatic amino acids supplementation and changes in the cell wall chemical composition and architecture. Moreover, it was shown that mutant strains exhibited attenuated virulence in Galleria mellonella larvae infection model. In another study, a $C$. albicans mutant strain was constructed, in which one $A R O 1$ gene allele was deleted and replaced by the $A R G 4$ selection marker and the second allele was inactivated using poly-adenosine insertion method (Tournu et al. 2019). One study revealed that 


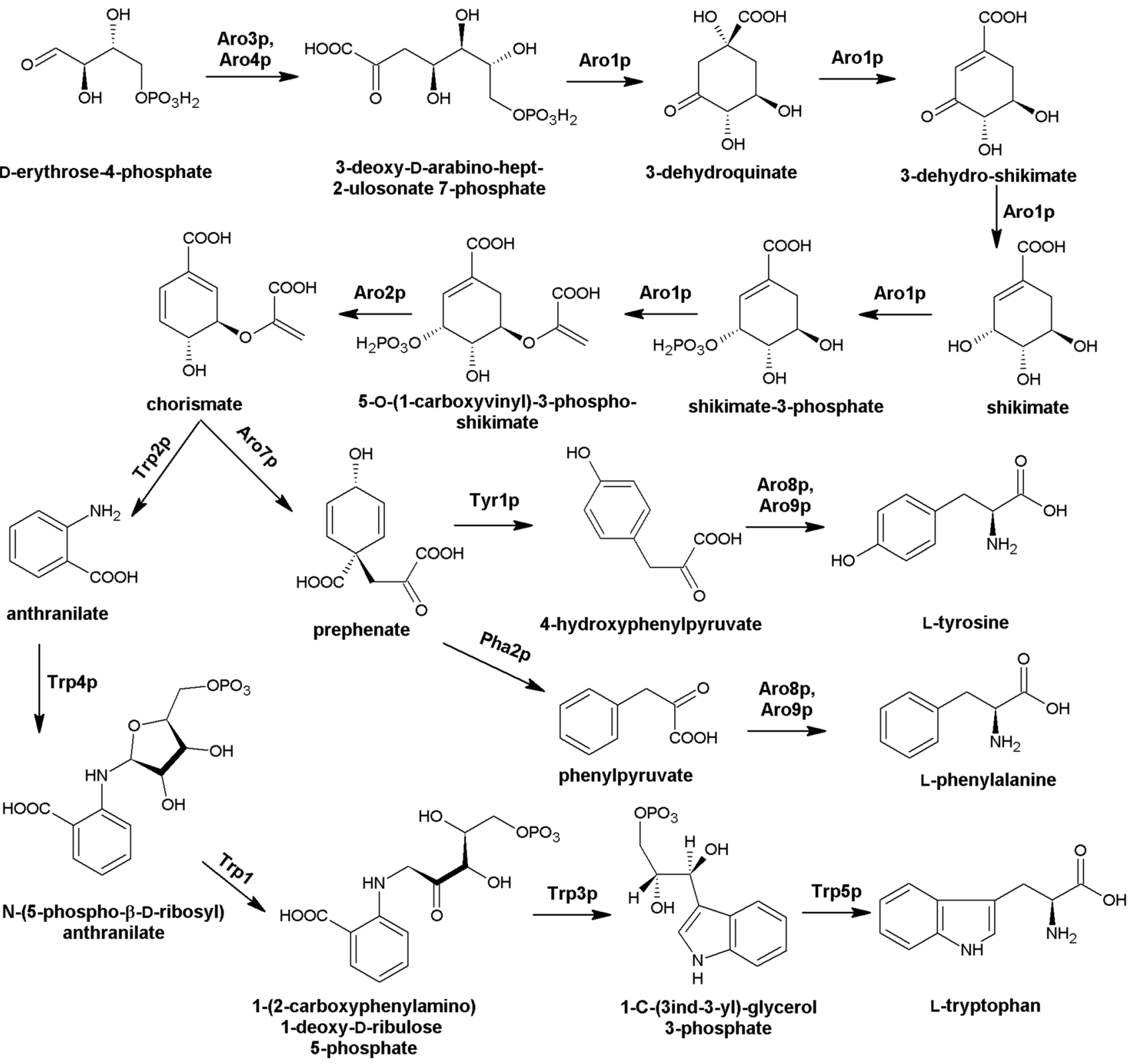

Fig. 7 Fungal shikimate pathway. Aro1p EC 2.5.1.19, EC 4.2.1.10, EC 4.2.3.4, EC 1.1.1.25, EC 2.7.1.71 pentafunctional AROM polypeptide; Aro2p EC 4.2.3.5 chorismate synthase; Aro3p, Aro4p EC 2.5.1.54 3-deoxy-7-phosphoheptulonate synthase; Aro7p EC 5.4.99.5 chorismate mutase; Aro8p, Aro9p EC 2.6.1.57, EC 2.6.1.39 aromatic amino acid/2-aminoadipate transaminase; Pha2p EC 4.2.1.51

the deletion strain could not grow in any standard growth medium, yet the growth could be restored with supplementation of $10 \mathrm{mM}$ aromatic amino acids as the sole nitrogen source, therefore, it was concluded that AROI gene is not essential in C. albicans. No successful inhibitors of fungal Aro1 $\mathrm{p}$ are known, however, a popular herbicide glyphosate (Fig. 8, compound 1) inhibits the plant 3-phosphoshikimate 1-carboxyvinyltransferase EC 2.5.1.19, that is said to be an orthologue of yeast Aro1p (Rong-Mullins et al. 2017). A prephenate dehydratase; Trp1p EC 5.3.1.24 phosphoribosylanthranilate isomerase; Trp2p EC 4.1.3.27 anthranilate synthase; Trp3p EC 4.1.1.48 indole-3-glycerol-phosphate synthase; Trp4p EC 2.4.2.18 anthranilate phosphoribosyltransferase; Trp5p EC 4.2.1.20 tryptophan synthase; Tyr1p EC 1.3.1.13 prephenate dehydrogenase $(\mathrm{NADP}(+))$. On the base of (Caspi et al. 2018)

study conducted on various $S$. cerevisiae strains showed that glyphosate indeed affected the growth of yeast strains, but not all at the same rate (Rong-Mullins et al. 2017). Additionally, AROI gene-deficient mutants were constructed to investigate whether glyphosate targets yeast Aro1p. Interestingly, most mutant strains were viable, except for S. cerevisiae RM11, a wine yard isolate. Surprisingly enough, AROI deficient mutant cells grown in YM medium with glyphosate, showed no difference in growth rate compared 


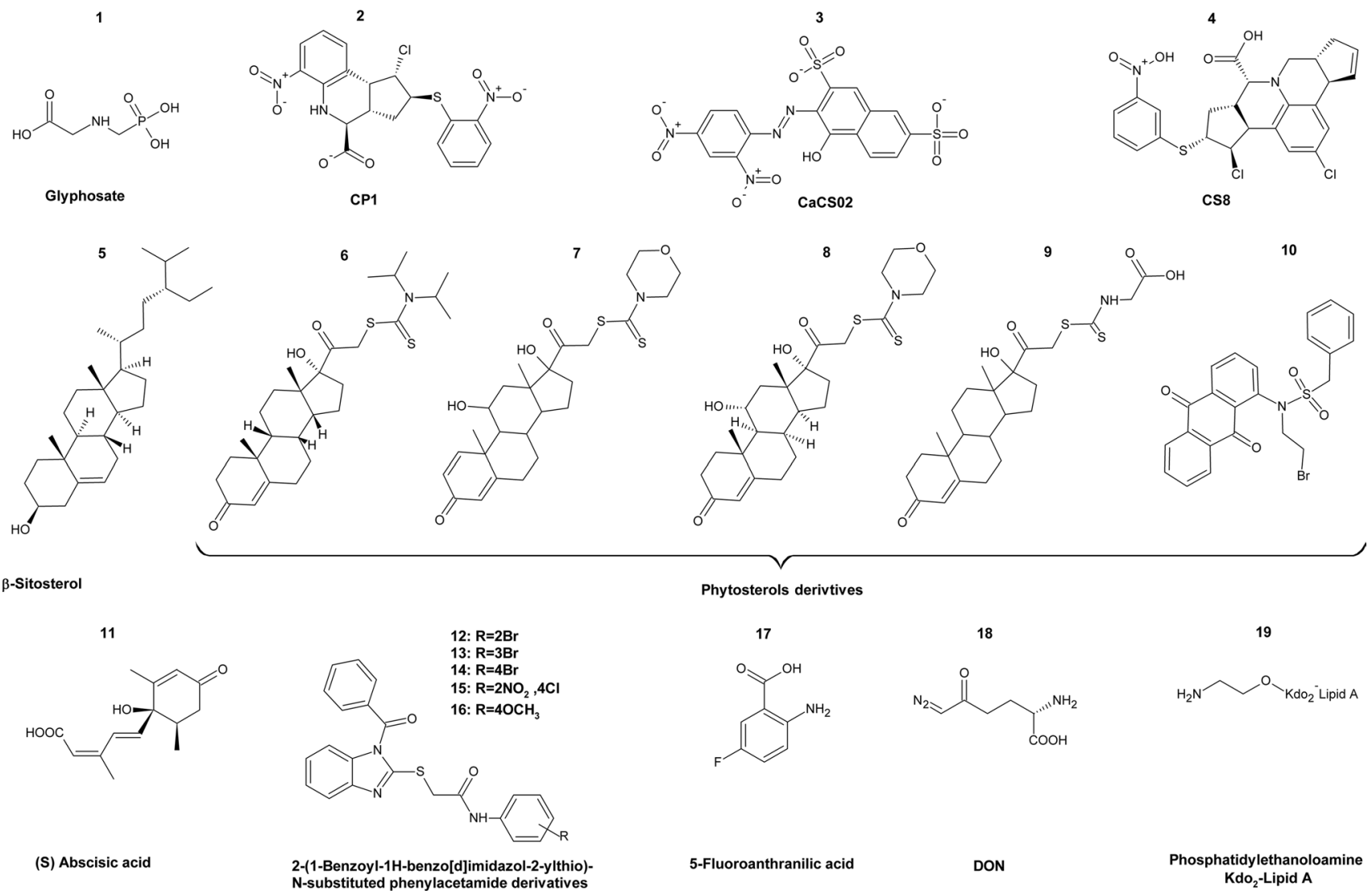

Fig. 8 Inhibitors of fungal enzymes from the shikimate pathway. Compound 1 Glyphosate; compound $2 \mathrm{CP} 1$; compound 3 CaCS02; compound 4 CS8; compound $5 \beta$-Sitosterol; compounds 6-10 Phytosterols derivatives; compound 11 (S) Abscisic acid; compounds

to the wild type. The study also tested whether supplementation of tyrosine, tryptophan, or phenylalanine would affect arol $\Delta$ yeasts growth rate in the presence of glyphosate. It was revealed that $S$. cerevisiae $\mathrm{S} 288$ c arold (a laboratory strain) were more sensitive to glyphosate than the wild type, while $S$. cerevisiae YJM789 arold (clinical isolate) mutant was more resistant to glyphosate than the wild type. It was later concluded that the growth variation of tested yeasts was not due to polymorphisms within $A R O 1$, but it was rather caused by genetic variation in the amino acid permease and ABC multiple drug transporter. Nonetheless, glyphosate not only inhibits Aro1p, but probably also other non-canonical targets, but that inquiry requires further investigation.

A branch point enzyme of the shikimate pathway, chorismate synthase, is encoded by ARO2 gene. Singh et al. (2010) identified and characterized ARO2 gene in Verticillium longisporum fungal plant pathogen, using a novel RNA-mediated gene silencing method. Reduction of the expression of both Aro2p encoding isogenes (ARO2-1, ARO2-2) by $80 \%$ resulted in a bradytrophic character, that is, a leaky auxotrophic mutant for aromatic amino acids. Constructed strains
12-16 2-(1-Benzoyl-1H-benzo[d]imidazol-2-ylthio)- $N$-substituted phenylacetamide derivatives; compound 17 5-Fluoroanthranilic acid; compound 18 DON; compound 19 Phospatidylethanoloamine Kdo2Lipid A

exhibited significantly reduced virulence towards the plant host Brassica napus compared to the wild type. Recently, with the help of $S$. cerevisiae chorismate synthase structure as a template, homology modeling of three-dimensional structure of Paracoccidioides brasiliensis enzyme was made (Rodrigues-Vendramini et al. 2019). This enabled a virtual screening search for potential inhibitors and molecular dynamics that resulted in one best hit compound CP1 (Fig. 8, compound 2). In vitro analysis of CP1 compound revealed that it binds to chorismate synthase and inhibits its activity with $\mathrm{IC}_{50}$ of $47 \mu \mathrm{M}$. What is more, $\mathrm{CP} 1$ displayed antifungal activity towards Paracoccidioides spp. with MIC values of 2-16 $\mu \mathrm{g} \mathrm{mL}^{-1}$ and $16-32 \mu \mathrm{g} \mathrm{mL}^{-1}$ towards $P$. brasiliensis and $P$. lutzii, respectively. In vivo studies on a mouse infection model proved CP1 compound was highly effective in treating paracoccidioidomycosis, by reducing fungal burden in the lungs and inflammatory response. It is important to note that CP1 exhibited no cytotoxic effect on human cell lines. Taken together, CP1 seems to be a promising antifungal agent that should be considered as a lead compound for the development of novel chorismate synthase inhibitors. 
Not long after, the amino acid sequence of $C$. albicans Aro2p was used for modeling the enzyme's 3D structure and a large-scale virtual screening (Bueno et al. 2019a). As a result, two novel potential inhibitors of chorismate synthase were identified, $\mathrm{CaCSO} 2$ and CS8 (Fig. 8, compounds 3-4), where the last one shows high resemblance to $\mathrm{CP} 1$ structure. Antifungal in vitro activity of both compounds against $C$. albicans and $P$. brasiliensis strains was determined. MIC values of compounds $\mathrm{CaCS} 02$ and CS8 towards P. brasiliensis were $32 \mu \mathrm{g} \mathrm{mL}^{-1}$ and $512 \mu \mathrm{g} \mathrm{mL}^{-1}$, respectively, however, no antifungal activity against $C$. albicans was observed. $\mathrm{CaCSO} 2$ inhibited the activity of $P$. brasiliensis Aro2p with $\mathrm{IC}_{50}$ value of $29 \mu \mathrm{M}$. Similarly, to CP1, CaCS02 appeared not cytotoxic to mammalian cell lines, even more it displayed a synergistic effect with amphotericin B, thus demonstrating potential activity in a combination antifungal therapy. Recently, another 3D modeling study of Aro2p structure from Alternaria arborescens plant pathogen was conducted (Choudhary et al. 2020). Natural product database screening identified 2861 compounds as potential inhibitors of A. arborescens chorismate synthase. Further computer-aided analysis selected five most potent compounds with a cyclopentaphenanthrene ring backbone (Fig. 8 compounds 6-10), similar to the one found in plant phytosterols: $\beta$-sitosterol (Fig. 8 compound 5). All identified inhibitors displayed selectivity towards pathogen's Aro2p, but only five compounds were used for further analysis. Molecular dynamics of enzyme-inhibitor complexes showed that only chorismate synthase- $\beta$-sitosterol complex acquired stability. Moreover, $\beta$-sitosterol displayed a significant reduction of $A$. arborescens growth in in vivo antifungal bioassay. This study shows that natural $\beta$-sitosterol could be useful in taming fungal pathogens in eco-friendly manner.

Chorismate mutase is encoded by the $A R O 7$ gene and is the enzyme catalyzing the first committed step that leads to the biosynthesis of L-phenylalanine and L-tyrosine, dividing it from the L-tryptophan biosynthesis branch. Aro7p catalyzes prephenate formation from chorismate. Recently, the chorismate mutase activity was described in Trichoderma parareesei, a filamentous fungus working as a biofungicide by protecting plants against pathogens. Successful plant colonization by Trichoderma spp. is considered being a major cause of its beneficial effects (Pérez et al. 2015). Silencing of $T$. parareesei ARO7 gene was evaluated in in vitro plant assays. It was reported that mutant cells exhibited a reduced ability to colonize plant roots. Additionally, plants colonized by $A R O 7$ silenced mutants were more sensitive to $B$. cinerea infection and displayed significantly lower growth parameters. It was, therefore, concluded that chorismate mutase might be involved in the biocontrol potential of $T$. parareese $i$ and is required for maintaining balanced interactions with plants. Fungal Aro7p still needs to be investigated. A homology modeling study was performed for C. albicans,
C. parapsilosis, A. niger, and T. rubrum putative chorismate mutase structures, to enable rational drug design for potential Aro7p inhibitors that could work as antifungal agents (Khedr et al. 2018). Previously, it was discovered that endooxabicyclic and aza-bicyclic compounds act as transition state inhibitors of chorismate mutase, and thus were used for the development of a pharmacophore model for virtual screening analysis (Sträter et al. 1997; Hediger 2004; Khedr et al. 2018). Screen of 160.00 lead-like compounds resulted in the identification of 25 compounds that fulfilled Lipinski's rule of five and exhibited the lowest RMSD values. Two compounds were used for structure similarity search of a potential Aro7p inhibitor that would be easy to synthesize; (S) abscisic acid (Fig. 8, compound 11) sheared 98\% similarity and was chosen for further analysis. Abscisic acid is a natural sesquiterpene phytohormone that regulates plant growth and development and plays an important role in plant responses to stresses. (S) Abscisic acid's ability to inhibit Aro7p was tested via inhibition of phenylpyruvate production; the results suggested that indeed (S) abscisic acid targets chorismate mutase. However, the inhibition rate of abscisic acid was compared to Aro7p inhibition by its natural allosteric inhibitor-tyrosine, and it was shown that tyrosine is 2-3 times more potent than ( $\mathrm{S}$ ) abscisic acid. Nonetheless, in vitro analysis of the antifungal properties of (S) abscisic acid revealed antifungal activity against $C$. parapsilosis and T. rubrum (MIC $62.5 \mu \mathrm{g} \mathrm{mL}^{-1}$ ) and C. albicans and $A$. niger (MIC $125 \mu \mathrm{g} \mathrm{mL}^{-1}$ ). Several potential inhibitors of Aro7p were found among 2-(1-benzoyl-1H-benzo[d] imidazol-2-ylthio)- $N$-substituted acetamides derivatives (Yadav et al. 2018). Four derivatives (Fig. 8, compounds 12-15) displayed excellent antifungal properties with MIC values ranging from 0.013 to $0.027 \mu \mathrm{g} \mathrm{m}^{-1}$ against $C$. albicans and $A$. niger, for comparison fluconazole minimal inhibitory concentration is $0.47 \mu \mathrm{g} \mathrm{mL}^{-1}$. These compounds were also effective against several bacteria species such as S. aureus, B. cereus, B. subtillis, S. typhi, and E. coli (MIC $0.027 \mu \mathrm{g} \mathrm{mL}^{-1}$ ). All the 20 found derivatives were tested for chorismate mutase inhibition activity, yet only 1 derivative (Fig. 8, compound 16) was proven to moderately inhibit mycobacterial Aro7p by 58.23\%. It is still unclear whether 2-(1-benzoyl-1H-benzo[d]imidazol-2-ylthio)-N-substituted acetamide derivatives work as fungal Aro7p inhibitors.

L-Tryptophan biosynthesis starts at the branch point, i.e., chorismate, and involves five unique steps catalyzed by anthranilate synthase (Trp2p), anthranilate phosphoribosyltransferase (Trp4p), phosphoribosylanthranilate isomerase (Trp1p), indole-3-glycerol-phosphate synthase (Trp3p) and lastly tryptophan synthase (Trp5p). All these enzymes have been characterized in $C$. neoformans cells and interestingly, $S$. cerevisiae phosphoribosylanthranilate isomerase encoded by TRPl gene, in C. neoformans cells is encoded by TRP3 gene. Even more, it was reported 
that L-tryptophan biosynthetic pathway is essential in $C$. neoformans, as revealed by iRNA silencing of TRP 3 and TRP5 genes (Fernandes et al. 2015). The study showed that TRP3 mutants were lethal when grown in YNB medium with galactose and ammonium sulfate as a sole nitrogen source, whereas TRP5 mutant cells exhibited significantly reduced growth. For both mutants, growth could not be rescued by supplementation of tryptophan. The same phenomenon was discovered for TRP3 silenced mutants when grown on YNB medium with galactose and proline as the only nitrogen source, however, in this case, growth could be slightly improved with tryptophan supplementation. The TRP5 mutant could also uptake tryptophan in the proline presence. Notably, both TRP3 and TRP5 C. neoformans mutants remained vital in YNB medium with dextrose, regardless of nitrogen source or tryptophan addition. It was concluded that the growth improvement caused by the use of proline as the sole nitrogen source was probably due to more efficient intracellular tryptophan transport. Moreover, L-tryptophan biosynthesis pathway was a target of an antimetabolite 5-fluoroanthranilic acid (Fig. 8, compound 17), since it caused complete cell growth inhibition in YNB medium supplemented with tryptophan. 5-Fluoroanthranilic acid serves as a substrate for Trp4p and disturbs cell growth by generating toxic tryptophan analogues. Additionally, a minimum inhibitory concentration assay was conducted for a glutamine analogue, 6-diazo-5-oxo-L-norleucine (DON) (Fig. 8, compound 18) targeting Trp2p. DON inhibits $C$. neoformans growth at the $\mu$ molar scale in rich medium, with MICs of $62.5 \mu \mathrm{M}$ and $125 \mu \mathrm{M}$ depending on the strain (Fernandes et al. 2015). Recently, Aspergillus fumigatus genome has been evaluated and as a result, five essential genes were identified among which there was a TRP5 gene-encoding tryptophan synthase (Srivastava et al. 2018). By means of homology modelling, Trp5p structure was obtained and then screened against a small molecule pathway database. Further docking studies identified one potential A. fumigatus tryptophan synthase inhibitor: phosphatidylethanolamine $\mathrm{kdo}_{2}$-lipid A (Fig. 8, compound 19). However, up to now, there are no reports on in vitro or in vivo assays of this compound as a potential antifungal agent.

\section{Protein biosynthesis}

Protein biosynthesis is essential for pathogen proliferation within the human host, and it involves the cooperation of enzymes catalyzing the processes of transcription, translation, and post-translational processing. Enzymes involved in the above processes are investigated as potential targets for novel antifungal therapies, in fact a few have already been proposed as targets for antibacterial, antiparasitic and antifungal drugs (Liu et al. 2018). Herein, we would like to focus on fungal protein biosynthesis inhibitors targeting aminoacyl-tRNA synthetases (aaRSs), elongation factors, $N$-myristoyltransferases (NMTs) and enzymes involved in post-translational modifications.

\section{Aminoacyl-tRNA synthetases}

The fundamental process of all living organisms, protein biosynthesis is carried by ribosomes that translate the information encoded in the messenger RNA (mRNA) to the amino acid sequence of the synthesized protein. Ribosomes link individual amino acids with the help of cognate transfer RNAs (tRNAs) and specific aminoacyl-tRNA synthetases (aaRSs) EC 6.1.1. Aminoacyl-tRNA synthetases (aaRSs) exist in all organisms and are essential for protein biosynthesis. AaRSs fulfill two important roles in protein translation: they mediate the condensation of the correct amino acids and its homologous tRNAs, but also they are the only enzymes responsible for ensuring the fidelity of translation. Up to now, 23 different aaRSs have been described which are named according to the aminoacyl-tRNA product generated; one for each of the 20 proteinogenic amino acids, with an exception for lysine that has 2 corresponding aaRSs, and 2 other pyrrolysyl-tRNA synthetase EC 6.1.1.26 and $O$-phosphoseryl-tRNA synthetase EC 6.1.1.27 found only in some bacteria and archaea (Rubio Gomez and Ibba 2020). Condensation of the tRNA molecule with the corresponding amino acid catalyzed by aaRSs involves two-step reaction (Fig. 9). In the first step, aaRSs utilizes ATP molecule to form enzyme-bound aminoacyl-adenylate intermediate, and the subsequent second step involves transfer of the aminoacyl group to the $3^{\prime}$ end of the homologous tRNA.

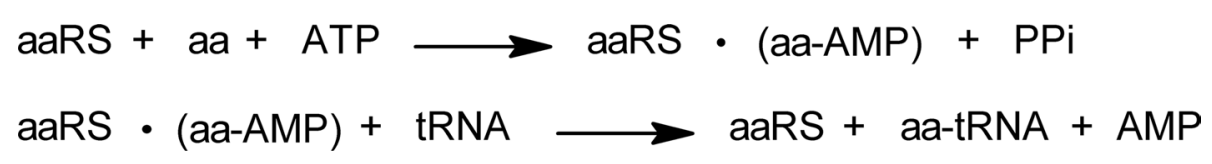

Fig. 9 Reactions catalyzed by aaRSs. aa Amino acid; (aa-AMP) Enzyme-bound aminoacyl-adenylate intermediate; aaRS aminoacyl-tRNA synthetases; aa-tRNA aminoacyl-tRNA; AMP adenosine monophosphate; ATP adenosine triphosphate; PPi inorganic pyrophosphate; tRNA transfer RNA 
Due to their major role in protein biosynthesis, aminoacyl-tRNA synthetases are regarded as potential targets for novel antifungal agents, despite the existing homology between aaRSs from different microorganisms. In fact, several inhibitors of bacterial and fungal aaRSs have been reported (Zhang and Ma 2019; Rubio Gomez and Ibba 2020). Among these inhibitors, cispentacin is worth mentioning, since it was effective against $C$. albicans in a mouse infection model (Oki et al. 1989). Its more potent derivative icofungipen, also known as BAY 10-888, reached phase II of clinical trials; despite exhibiting good clinical efficacy, its research has been discontinued due to side effects observed in human toxicity studies (McCarthy and Walsh 2018). AN2690, a derivative of borinic acid quinolone ester, known as tavaborole (Fig. 10, compound 1), is an inhibitor of leucyl-tRNA ${ }^{\text {Leu }}$ synthase EC 6.1.1.4 (LeuRS; aaRS charges tRNA ${ }^{\text {Leu }}$ with leucine) and is used in clinical treatment since 2014 (Rock et al. 2007; Markham 2014; Sharma and Sharma 2015). Tavaborole displays good antifungal activity against dermatophytes, Trichophyton mentagrophytes, and Trichophyton rubrum, primary cause of onychomycosis, with MICs values of $1-2 \mu \mathrm{g} \mathrm{m}^{-1}$ (Coronado et al. 2015). It is also active against $A$. fumigatus, Candida spp., and S. cerevisiae (MICs $0.25-4 \mu \mathrm{gL}^{-1}$ ), however, because of its short half-life span, it can only be used as a treatment for topical fungal infections of the nail (Gupta and Versteeg 2016). On the other hand, a recent study reported that tavaborole antifungal activity against molds and yeast from onychomycosis is lower than stated previously (MIC 4-16 $\mu \mathrm{g} \mathrm{mL}^{-1}$ ) (Abastabar et al. 2018). This suggests that this drug might not be the best candidate for the treatment of onychomycosis caused by Candida spp., Aspergillus spp., and dermatophytes. AN2690 was also found to inhibit LeuRS of Leishmania, whereas its derivative ZCL039 was active against $S$. pneumonia with MIC value of $5 \mu \mathrm{g} \mathrm{mL}^{-1}$ (Hu et al. 2013; Manhas et al. 2018).

Another example of aaRS inhibitor is borrelidin (Fig. 10, compound 2), a nitrile containing 18-membered polyketide macrolide that inhibits threonyl-tRNA ${ }^{\text {Thr }}$ synthetase EC 6.1.1.3 (ThrRS; aaRS charge tRNA ${ }^{\mathrm{Thr}}$ with threonine). This compound has a broad-spectrum activity against viruses, bacteria, and some fungi (Lumb et al. 1965; Gao et al. 2012). Despite its promising properties, borrelidin is not used in clinical practice because of its strong cytoxic effect in animal cells, thus suggesting that ThrRS might not be the only target of borrelidin (Wilkinson et al. 2006). A recent<smiles>OB1OCc2cc(F)ccc21</smiles>

Tavaborole

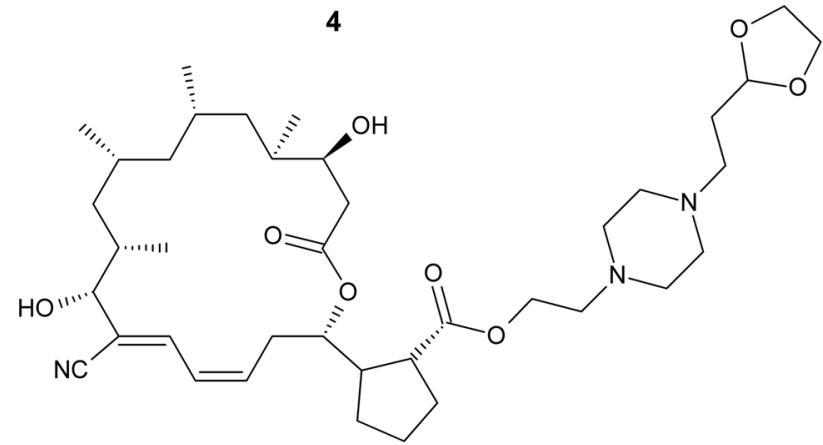

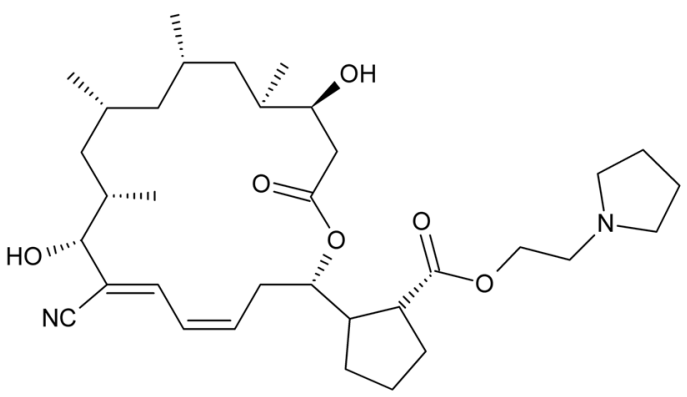

$\mathrm{BN}-3 \mathrm{~b}$

Borrelidin derivtives

Fig. 10 Inhibitors of fungal aminoacyl-tRNA synthetases. Compound 1 Tavaborole; compound 2 Borrelidin; compound 3 BN-3b; compound 4-5 Borrelidin derivatives 
study synthesized a library of 47 borrelidin derivatives and evaluated their antifungal activity and cytotoxicity ( $\mathrm{Hu}$ et al. 2018). The results indicated one compound, BN-3b (Fig. 10, compound 3) that was effective against $C$. albicans and $C$. parapsilosis with MIC values of $50 \mu \mathrm{g} \mathrm{mL}^{-1}$ and $12.5 \mu \mathrm{g} \mathrm{mL}{ }^{-1}$, respectively. Two other derivatives (Fig. 10, compounds 4-5) had an inhibitory effect on A. fumigatus with $\mathrm{MIC}=12.5 \mu \mathrm{g} \mathrm{mL}^{-1}$. All tested strains were unaffected by borrelidin at a high concentration of $100 \mu \mathrm{g} \mathrm{mL}^{-1}$. Structure-activity relationship analysis revealed that the cyano group is essential for antifungal activity that can be improved by introduction of $\left(-\mathrm{OCH}_{2} \mathrm{CH}_{2} \mathrm{~N}-\right)$ fragment into the carboxyl of borrelidin structure. Molecular docking analysis with X-ray structure of yeast mitochondrial ThrRS showed that the introduced carboxyl substituents could favor extra interaction with ThrRS of pathogenic fungi. Above derivatives displayed far better selectivity towards fungal cells than the parent compound. Later on, the same research group further investigated $\mathrm{BN}-3 \mathrm{~b}$ derivative and revealed that it stimulated endogenous reactive oxygen species (ROS) accumulation, leading to an antifungal effect ( $\mathrm{Su}$ et al. 2020). Additionally, BN-3b severely damaged C. albicans cell membrane and inhibited hyphal formation. Moreover, in vivo studies showed that $\mathrm{BN}-3 \mathrm{~b}$ significantly prolonged survival and decreased fungal burden in a mouse model of disseminated candidiasis. These findings reveal that induction of endogenous ROS plays a major role in the antifungal activity of BN-3b. However, previously revealed interaction of BN-3b with ThrRS might also be important for antifungal activity, yet it needs to be further verified. Nonetheless, $\mathrm{BN}-3 \mathrm{~b}$ should be regarded as a promising lead for the development of novel antifungal agents.

\section{Elongation factors}

Protein biosynthesis occurs via the translational machinery, in which tRNA interacts with the ribosome in three stages: initiation, elongation, and termination. During the elongation stage, a new amino acid is added to the growing polypeptide chain via a three-step process involving selection of an appropriate aminoacyl-tRNA, formation of a peptide bond and finally translocation. Translocation is a crucial step in the process of protein biosynthesis, incorporating elongation factors associated with GTP hydrolysis (Berg et al. 2015). Elongation factors are potential molecular targets for novel antifungal agents not only because of their essential role in protein biosynthesis but also because of exploitable differences between mammalian and fungal counterparts. Fungal translation is unique since it requires three factors: elongation factor 1 (eEF1A), elongation factor 2 (eEF2), and elongation factor 3 (eEF3). In mammalian cells, eEF2 is functionally distinct from the fungal counterpart, while eEF3 does not exist (Dever et al. 2016).
Sordarins are protein biosynthesis inhibitors that work in a dual way. They bind to eEF2 and block translocation by stabilization of the eEF2-ribosome complex, but also inhibit eEF2-ATP mediated ribosome splitting (Chakraborty et al. 2013). It is noteworthy that eEF2 are highly conserved among all eukaryotes, however, sordarins interact specifically with eEF2 in yeast and filamentous fungi while failing to do the same in human cells. Several sordarin derivatives exhibiting a broad spectrum of antifungal activity have already been reported ( $\mathrm{Di}$ Santo 2008). In particular, compound R-135853 (Fig. 11, compound 1), a derivative of sordarin isolated from Zopfiella marina, was a potent antifungal agent against $C$. albicans, C. glabrata, C. guilliermondii and C. neoformans with MICs in the $0.016-0.5 \mu \mathrm{g} \mathrm{mL}^{-1}$ range. Additionally, R-135853 was effective in C. albicans infected mice model (Kamai et al. 2005). Regueiro-Ren et al. (Regueiro-Ren et al. 2002) prepared core-modified sordaricin (aglycone of sordarins) derivatives via biotransformation of Nocardia spp. All new compounds exhibit antifungal activity. The most potent two (Fig. 11, compounds 2-3) of them inhibit $90 \%$ growth of $C$. albicans and $C$. glabrata at $0.125-8 \mu \mathrm{g} \mathrm{mL}^{-1}$ concentration. A year after, Serrano-Wu et al. (Serrano-Wu et al. 2003) synthesized $5 '$ - and 5'-6'-substituted azasordarin derivatives, which were the first sordarins active against Aspergillus spp.. 5'-Me analogues (Fig. 11, compounds 4-5) were more active against Candida spp., C. neoformans, and Aspergillus spp. than 6'-Me counterparts and registered MIC values $<0.06-32 \mu \mathrm{g} \mathrm{mL} \mathrm{m}^{-1}$. Substitution of $5^{\prime}$-position broadened the antifungal spectrum of the azasordarins. $5^{\prime}$ Spirocyclopentyl-analogue (Fig. 11, compound 6) exhibited the best MIC profile $<0.008-8 \mu \mathrm{g} \mathrm{mL}^{-1}$, while $i$-Pr substitution in the 5 '-position improved the compound's metabolic stability and plasma half-life compared to other azasordarins. A computer-aided design study indicated sordarin aminopyrrole derivative (Fig. 11, compound 7) as a potential fungicidal agent, which is ineffective against human eEF2 (Chakraborty et al. 2016). Introduction of 2-aminopyrrole group at C61 position might increase the binding affinity with fungal eEF2 and simultaneously decrease interactions with the human eEF2 cavity, suggesting 2-aminopyrole as a good template for the design of novel antifungal drugs. Another study discovered six novel sordarins from Curvularia hawaiiensis TA26-15, a marine-derived fungus, possessing a rare in nature sordarose residue with a spiro 1,3-dioxolan-4-one ring (Zhang et al. 2019). Isolated compounds (Fig. 11, compounds 8-13) were tested for antifungal activity and displayed MIC values in the range of $2.9-13 \mu \mathrm{M}$ against C. albicans. Further analysis indicated that the $\mathrm{C} 2$ carboxylic acid determined antifungal activity, however, aliphatic acid side chain length may contribute to this effect. 


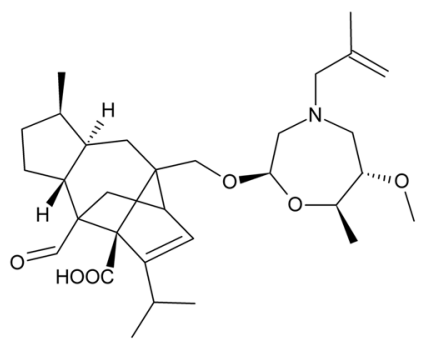

R-135853

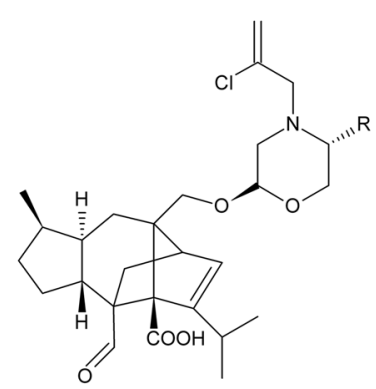

Azasordarin derivatives

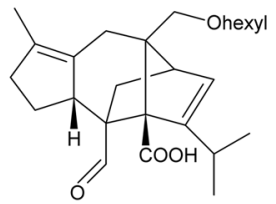

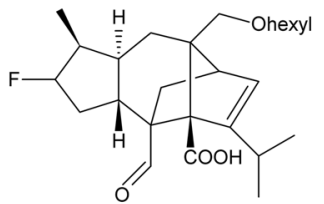

Sordaricin derivatives

4: $\mathrm{R}=\mathrm{Me}$

5: $\mathrm{R}=i-\mathrm{Pr}$

6: $R=$ sprirocyclopentyl

14

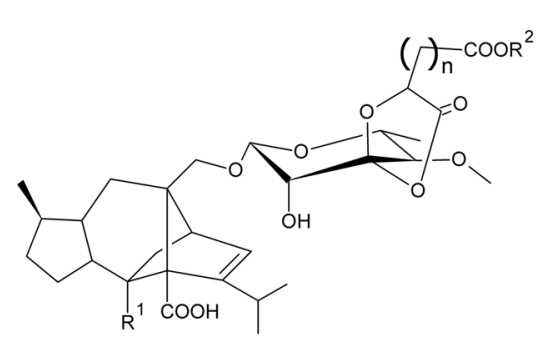

Sordarin diterpene glycosides
8: $\mathbf{R}^{1}=\mathrm{CHO}, \quad \mathbf{R}^{2}=\mathrm{H}, \quad n=5$

9: $\mathbf{R}^{1}=\mathrm{CHO}, \quad \mathbf{R}^{2}=\mathbf{H}, \quad \mathbf{n = 3}$

10: $\mathbf{R}^{1}=\mathrm{CHO}, \quad \mathrm{R}^{2}=\mathrm{CH}_{3}, \mathrm{n}=3$

11: $\mathbf{R}^{1}=\mathrm{CHO}, \quad \mathbf{R}^{2}=\mathrm{CH}_{3}, \mathbf{n = 7}$

12: $R^{1}=\mathrm{COOH}, R^{2}=H, \quad n=7$

13: $\mathbf{R}^{1}=\mathrm{COOH}, \mathrm{R}^{2}=\mathrm{CH}_{3}, \mathrm{n}=7$ derivative

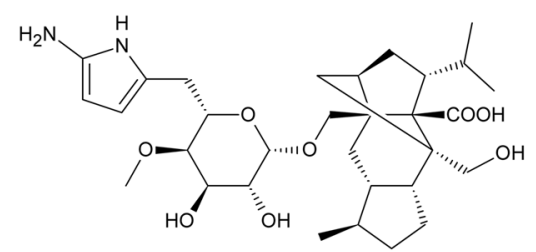

Aminopyrrole sordarin

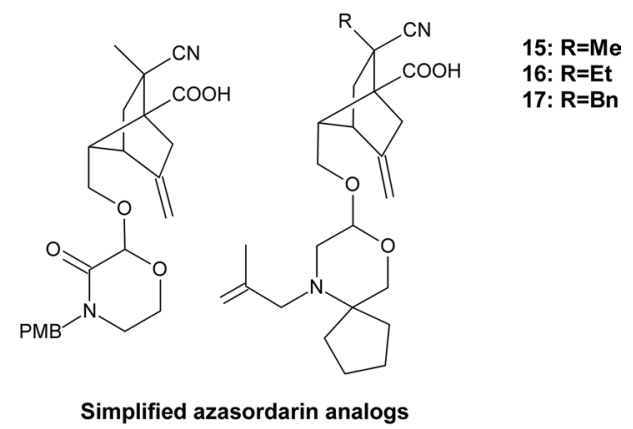

19
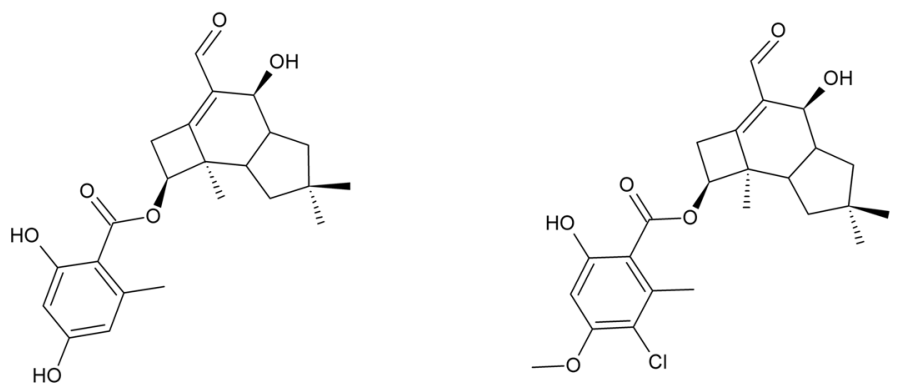

Arnamial

Fig. 11 Inhibitors of fungal elongation factors. Compound 1 R-135853; compounds 2-3 Sordaricin derivatives; compounds 4-6 Azasordarin derivatives; compound 7 Aminopyrrole sordarin deriva- tive; compounds 8-13 Sordarin diterpene glycosides; compounds 14-17 Simplified azasordarin analogs; compound 18 DAO; compound 19 Arnamial 
Wu and Dockendorff (2018) designed novel scaffolds of sordarin derivatives that could be more easily modified to improve properties such as metabolic stability and antifungal activity. Generated novel scaffolds maintained the pharmacophore of sordarin, which is a carboxylic acid at $\mathrm{C} 1$ and a nitrile or aldehyde group at $\mathrm{C} 2$ of the bicyclic core, additionally, a complex diterpene core was replaced with a simplified bicyclic scaffold. Docking analysis revealed that simplified sordarin analogs exhibited comparable docking poses to the parent sordarin and similar docking scores to compounds that have been reported to be effective against $S$. cerevisiae. These findings may lead to the design of a soradrin derivative with improved properties. Not long after, the same research group synthesized a series of new simplified azasordarin analogs with bicyclo[2.2.1] heptane core and incorporation of morpholino glycone; previously reported in sordarin derivatives with broad-spectrum antifungal activity $(\mathrm{Wu}$ and Dockendorff 2019). Generated novel derivatives as isomeric mixtures (Fig. 11, compounds 14-17) were subjected to antifungal microdilution assays, but no growth inhibition was observed against $C$. albicans, A. fumigatus, C. parapsilosis and Paecilomyces variotii at concentration up to $8 \mu \mathrm{g} \mathrm{mL}^{-1}$ or $4 \mu \mathrm{g} \mathrm{mL} \mathrm{m}^{-1}$.

As far as we know, despite pharmaceutical industry efforts to develop semisynthetic sordarin analogs, no eEF2 inhibitors have advanced to clinical stages.

Recently, it was discovered that eEF2 can also be inhibited by natural products of the honey mushroom Armillaria mellea melleolides (Dörfer et al. 2019). Melleolides represent a structurally diverse group of polyketidesesquiterpene hybrids exerting potent antifungal effects against Aspergilli and various other fungi species. Two identified compounds, dehydroarmillyl orsellinate (DAO) and arnamial (Fig. 11, compounds 18-19) containing $\Delta^{2,4}$-double bond, crucial for antifungal activity, were reported as potent inhibitors of eEF2 in Aspergillus and probably Candida strains. DAO caused growth inhibition of A. nidulans, Candida albicans, Candida parapsilosis, and Candida lusitaniae, however, Candida glabrata and $S$. cerevisiae were unaffected. Interestingly, $S$. cerevisiae and C. albicans were sensitive to sordarin, while A. nidulans and other tested fungal species were resistant. From these observations, it was suggested that sordarins and melleolides target dissimilar sites in eEF2. Elongation factor 3 is not found in mammalian cells, thus it would make a perfect molecular target for antifungal drugs. In fact, in fungal cells, eEF3 encoded by the YEF3 gene is essential for translation and cell viability (Dever et al. 2016). Although up to our knowledge, there are no reports of any potential inhibitors targeting fungal eEF3. Taken together, translational elongation factors seem to be a valid source of molecular targets for novel antifungal chemotherapy.

\section{Glycylpeptide $\mathbf{N}$-tetradecanoyltransferase (N-Myristoyltransferase)}

Glycylpeptide $N$-tetradecanoyltransferase EC 2.3.1.97 known as $N$-myristoyltransferase (NMT) catalyzes cotranslational transfer of a myristoyl moiety from myristoylCoA (MYA) to the N-terminal glycine of proteins, followed by the removal of the methionine initiator residue. NMT is present in various eukaryotic organisms, however, there are clear differences in peptide substrate specificity between fungal and human enzymes. In fact, fungal NMT was proven to be essential for the growth and viability of $C$. albicans and C. neoformans (Lodge et al. 1994; Weinberg et al. 1995), while genetic disruption studies performed on A. fumigatus revealed that reduced expression of NMT encoding gene affected cell morphogenesis and cell wall integrity (Fang et al. 2015). $N$-Myristoyltransferase is, therefore, highly investigated as a potential therapeutic target for the treatment of pathogenic fungal infections. Up to now, there are several reports of various NMT inhibitors that include benzofuran derivatives, myristic acid analogues, and peptidomimetics (Liang et al. 2016). The most potent inhibitors reported are RO-09-4879 and FTR1335 (Fig. 12, compounds 1-2) displaying high and selective antifungal activity. RO-09-4879 inhibits growth of $C$. albicans, $C$. guilliermondii, C. tropicalis, C. parapsilosis with MIC values $0.11,0.44,0.11$, and $0.055 \mu \mathrm{M}$, respectively, while FTR1335 inhibits especially C. albicans, including fluconazole-resistant isolates with MIC value $0.78 \mu \mathrm{M}$ (Masubuchi et al. 2003; Ebara et al. 2005). Recently, a screening of inhibitor library led to discovery of a pyrazole sulphonamide derivative DDD86481 (Fig. 12, compound 3) that inhibited the A. fumigatus NMT enzyme with $\mathrm{IC}_{50}$ value $12 \mathrm{nM}$. Despite highly potent properties, DDD86481 turned out to be a poor fungicidal agent against A. fumigatus (MIC $925 \mu \mathrm{M}$ ), however, under partially repressive NMT encoding gene conditions, its fungicidal activity was improved (MIC $7 \mu \mathrm{M})$ (Fang et al. 2015). Liang et al. (Liang et al. 2016) designed and synthesized a series of novel benzofuran-triazole hybrids as potential inhibitors of NMT. Designed derivatives possessed a 1,2,3-triazole scaffold that was previously reported in various antifungal agents. Two of the synthesized derivatives (Fig. 12, compounds 4-5) exhibited antifungal activity against fluconazole-resistant $T$. rubrum and $C$. neoformans, with MIC in the range of 32-64 $\mu \mathrm{g} \mathrm{mL}^{-1}$, which makes them an asset for further research. In a more recent study, novel benzofuran-semicarbazide hybrids and 1,3-dialkoxybenzene-semicarbazide hybrids were identified as potential NMT inhibitors (Xu et al. 2019). Most of the identified compounds displayed in vitro antifungal activity against several fungal strains: C. albicans, A. fumigatus, T. rubrum, C. krusei and C. parapsilosis. Among all tested compounds, five derivatives (Fig. 12, compounds 6-10) were found to inhibit 
<smiles>Cc1c(COc2ccc(F)c(F)c2F)oc2cccc(OCCCNCc3cccnc3)c12</smiles>

RO-09-4879<smiles>O=C(Nc1ccc2nc(NC(=O)[C@H]3CCC[C@H](NCc4ccc5c(c4)CC=CC5)C3)sc2c1)C1CCCC1</smiles>

FTR1335
3

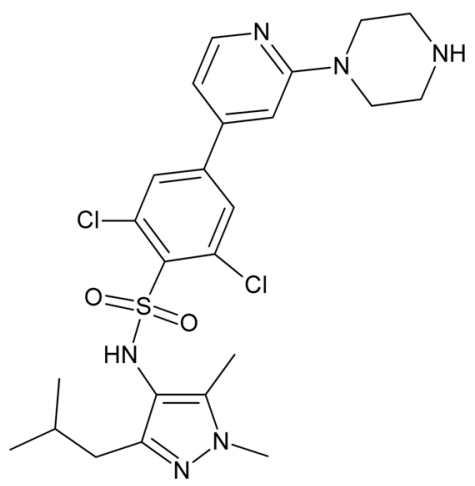

DDD86481<smiles>[R]Cc1ccccc1-n1cc(COc2cccc3oc(C(=O)c4ccc(F)cc4F)c(C)c23)nn1</smiles>

Benzofuran-triazole hybrids<smiles>[R][X]c1cccc(NC(=O)NNCCCOc2cccc(OCC(=O)c3ccc(F)cc3F)c2)c1</smiles>

\section{1,3-Dialkoxybenzene-semicarbazide} hybrids

\section{4: $\mathrm{R}=2-\mathrm{CH}_{3}$ 5: $\mathrm{R}=2,5-\mathrm{di}-\mathrm{CH}_{3}$}

8: $\mathrm{R}=\mathrm{H}$

9: $\mathrm{R}=4-\mathrm{CH}_{3}$ 10: $\mathrm{R}=2,5-\mathrm{di}-\mathrm{CH} 3$

Fig. 12 Inhibitors of fungal $N$-myristoyltransferase post-translational modifications. Compound 1 RO-09-4879; compound 2 FTR1335; compound 3 DDD86481; compounds 4-5 Benzofuran-triazole hybrids; compounds 6-7 Benzofuran-semicarbazide hybrids; com-

the growth of two fluconazole-resistant $C$. albicans strains isolated from AIDS patients, with MIC values between 2 and $32 \mu \mathrm{g} \mathrm{m}^{-1}$. Inhibitor of fungal NMT was also found pounds 8-10 1,3-Dialkoxybenzene-semicarbazide hybrids; compound 11 (E)-3-Benzylidene-6-(3-(phenethylamino)-propoxy)thiochroman4-one

among a series of synthesized novel thiochroman-4-one derivatives (Fig. 12, compound 11), which showed antifungal activity against $C$. albicans and $C$. neoformans with 
MIC of $0.5 \mu \mathrm{g} \mathrm{mL}^{-1}$ and $1 \mu \mathrm{g} \mathrm{mL}^{-1}$, respectively, values similar to those for amphotericin B (Zhong et al. 2017). The structure-activity relationship and molecular docking analysis indicated that the binding model of the found inhibitor to $C$. albicans NMT was consistent with the original NMT ligand R64. Taken together, thiochroman-4-one derivatives might be considered as new promising lead candidates for further development of novel antifungal agents.

Majority of eukaryotic proteins undergo reversible posttranslational modifications (PTM) that enable them to gain their final activity. These processes include acetylation, methylation, phosphorylation, glycosylation, and ubiquitination of protein molecules (Wassano et al. 2020). Reversible PTMs control various cell processes via regulation of protein function, the most important modification is acetylation of proteins that regulates translation, gene expression, and metabolism (Kuchler et al. 2016). Acetylation is an evolutionarily conserved process that involves acetyltransferase enzymes transmitting the acetyl group from a donor acetyl coenzyme A (CoA) to a suitable acceptor molecule. Histone acetyltransferases EC 2.3.1.48 (HATs) and histone deacetylases EC 3.5.1.98 (HADC) catalyze, respectively, the addition or removal of acetyl groups to or from lysine residues, most importantly in histone proteins, and have been identified as potential drug targets (Wassano et al. 2020). It was revealed that HAT/ HADC activities are required for $C$. albicans virulence. HATs also are involved in the morphogenetic yeast to hyphae transition, drug resistance and biofilm formation (Kuchler et al. 2016). One of the most potent Hos2p histone deacetylase EC 3.5.1.98 (HADC2) inhibitor is MGCD290 (Fig. 13, compound 1), which entered phase II of clinical trials in 2013 (Houšt et al. 2020). MGCD290 increases the susceptibility of Candida spp. and A. fumigatus to azole antifungals, however, alone it showed lower antifungal activity (MIC range 4-32 $\mu \mathrm{g} \mathrm{mL}^{-1}$ ) (Pfaller et al. 2009, 2015). Phase II of clinical trials exhibited that this compound did not increase the efficacy of fluconazole therapy in vivo, no further studies in this area are conducted (Gintjee et al. 2020). Recently, Han et al. (2020) discovered the first generation of sterol 14-alpha-demethylase/histone deacetylases CYP51/HDAC EC 1.14.14.154/ EC 3.5.1.98 dual inhibitors, which exhibited potent antifungal activity against azole-resistant candidiasis. One of the designed compounds (Fig. 13, compound 2) inhibited the activity of fungal CYP51/HDAC with an $\mathrm{IC}_{50}$ value of $0.16 \mu \mathrm{M}$. Moreover, it displayed excellent in vitro and in vivo antifungal activity against $C$. albicans and $C$. neoformans with $\mathrm{MIC}_{80}$ values of $0.125 \mu \mathrm{g} \mathrm{mL}^{-1}$ and $0.5 \mu \mathrm{g} \mathrm{mL}^{-1}$, respectively, and was active against azole-resistant clinical isolates with $\mathrm{MIC}_{80}$ values between 0.25 and $0.5 \mu \mathrm{gL}^{-1}$. The inhibitor also prolonged the survival time of mice infected with $C$. albicans and significantly decreased renal fungal burden.
1

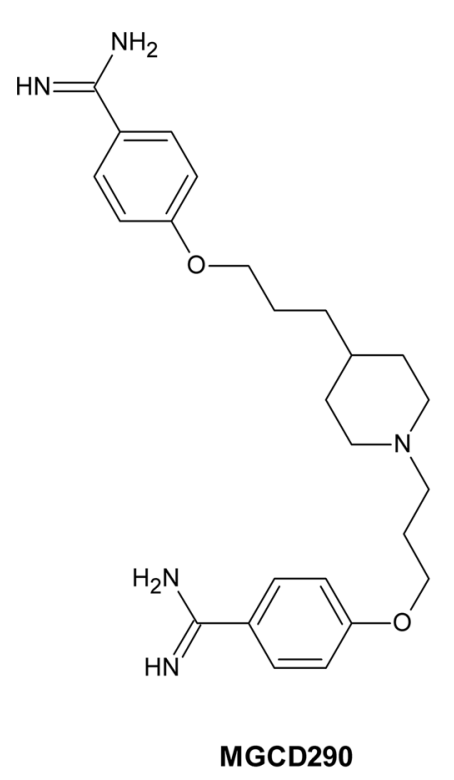

MGCD290
2

3<smiles>CN(Cc1ccc(OCCCOc2ccc(CC(=O)NO)cc2)cc1)CC(O)(Cn1cncn1)c1ccc(F)cc1F</smiles>

2-(4-(3-(4-(((2-(2,4-Difluorophenyl)-2-hydroxy-
3-(1H-1,2,4-triazol-1-yl)propyl)(methyl)amino)
methyl)phenoxy)propoxy)phenyl)-
N-hydroxyacetamide

CPTH2

Fig. 13 Inhibitors of fungal acetyltransferase enzymes involved in post-translational modifications. Compound 1 MGCD290; compound 2 2-(4-(3-(4-(((2-(2,4-Difluorophenyl)-2-hydroxy-3-(1H-1,2,4-triazol- 1-yl)propyl)(methyl)amino)methyl)phenoxy)propoxy)phenyl)- $N$-hydroxyacetamide; compound $3 \mathrm{CPTH} 2$ 
Antifungal activity was also proven for a known Gcn5p histone acetyltransferase EC 2.3.1.48 (HAT) inhibitor, cyclopentylidene-[4-(4-chlorophenyl)thiazol-2-yl)hydrazone (CPTH2) (Fig. 13, compound 3) (Chimenti et al. 2009; Tscherner and Kuchler 2019). CPTH2 exhibited selective antifungal activity towards CTG clade fungal species, but especially it had a significant fungicidal effect against $C$. albicans. This compound completely inhibited yeast growth and severely decreased its potential in $50 \mu \mathrm{M}$ and $25 \mu \mathrm{M}$ concentrations, respectively. CPTH2 was discovered to protect primary macrophages from Candida-mediated death. However, further studies revealed that $\mathrm{CPTH} 2$ antifungal effect is independent of direct Gcn5p inhibition, which suggests that Gcn5p might not be the only target of CPTH2, but this requires future verification. Nonetheless, post-translational modifications such as acetylation and deacetylation of proteins provide an interesting source of targets for novel inhibitors that could treat fungal diseases.

\section{Antifungal peptides targeting protein biosynthesis}

There are reports indicating that some peptides may inhibit protein biosynthesis and act as antimicrobial agents (Fernández de Ullivarri et al. 2020). In 2020, Velivelli et al. (2020) showed the fungicidal activity of peptide NCR044 from Medicago truncatula (barrelclover). NCR044 inhibits the growth of four economically important fungal pathogens: $F$. oxysporum with $\mathrm{IC}_{50}$ value of $0.52 \mu \mathrm{M}, B$. cinerea with $\mathrm{IC}_{50}$ value of $1.55 \mu \mathrm{M}, F$. graminearum and $F$. virguliforme with $\mathrm{IC}_{50}$ value of $1.93 \mu \mathrm{M}$ and $1.68 \mu \mathrm{M}$, respectively. Previously, it was also discovered that nine NCR peptides inhibit the growth of $C$. albicans with MIC values in the range of $10-25 \mu \mathrm{g} \mathrm{mL}^{-1}$, where NCR044 exhibited MIC of $11-12.5 \mu \mathrm{g} \mathrm{mL}{ }^{-1}$. Moreover, all tested peptides were found nontoxic for human cells, however, at higher concentrations, some were reported to affect the proliferation of human cells (Ördögh et al. 2014). These results bring insight into the therapeutic potential of NCR peptides in antifungal chemotherapy. The multistep antifungal mechanism of NCR044 includes an inhibition of translation. This is not the only case of a peptide with such mechanism of action. Méndez et al. (1996) showed that $\gamma$-hordothionin plant defensin from Hordeum vulgare endosperm, interferes with the chain elongation step of protein biosynthesis in the rabbit reticulocyte system, whereas $\omega$-hordothionin affects the initiation and elongation processes. However, this mechanism of action has never been associated with the antimicrobial activity of these compounds (de Oliveira Carvalho and Moreira Gomes 2012). Several other peptides, plant defensins, with antifungal activity inhibit protein biosynthesis in cell-free extract systems like RBAFP from Adzuckia angularia, PBAFP, WCBAFP, vulgarinin from Phaselus vulgaris, VaD1 from Vigna angularis, $\mathrm{SI}_{1}$ from Sorghum bicolor (Chen et al.
2005; Colilla et al. 1990; Osborn et al. 1995; Ye and Ng 2001; Wong and Ng 2005; Wong et al. 2006), but it is not known whether this mechanism of action is significant in vivo in inhibiting fungal growth (van der Weerden and Anderson 2013). This is related to the necessity for peptides to penetrate inside the cell, into the cytoplasm where the cell translation machinery resides. Some plant defensin are able to traverse the fungi plasma membrane, like $V r$ CRP from Vigna radiate, which inhibits the growth of Rhizoctonia solani (Chen et al. 2002). Whereas antibacterial peptides apidaecins, enter bacterial cell and inhibit protein biosynthesis in vivo in dose-dependent manner (Castle et al. 1999). A similar mechanism has also been proven for animal origin pleurocidin-based and PR-39. It was proven that membrane damaging is not a primal cause of antibacterial activity but rather an inhibition of macromolecular biosynthesis (Boman et al. 1993; Patrzykat et al. 2002).

\section{Conclusion}

Nowadays, there is a growing need for antifungal compounds whose mechanism of action differs completely from drugs used clinically. More than a decade has passed since introducing a new class of antifungal drugs that fight systemic mycoses, whereas there are known cases of fungi resistant to all approved oral drugs. The number of antifungal publications has more than doubled in the last 20 years, which proves the increased interest in this problem and the intensification of research into new compounds fighting mycosis. Finding a compound that kills fungi is easy; the problems that need to be dealt with are the selectivity of antifungals, their toxicity towards host cells, and environmental safety (in the case of compounds used in agriculture). Compounds that inhibit enzymes involved in amino acid biosynthesis, protein biosynthesis and post-translational modification pathways represent a new class of agents that give hope to overcoming these problems and fungal cross-resistance mechanisms. The information provided shows that the branched-chain amino acids, aromatic amino acids, and methionine biosynthetic pathways are particularly important for the virulence of fungal pathogens, however, the target potential of fungal elongation factors is clearly still unexploited. In this paper, we presented compounds with antifungal activity (from the period 2015 to 2020), the molecular targets which are the enzymes involved in the route that leads from amino acid biosynthesis to protein folding and its activation (Table 1). The enzymes described in our review: (1) belong to biosynthetic pathways that do not exist in human cells, or/and (2) their structure is functionally distinct from the human counterpart. We confirmed the potential of the described compounds by describing their effect on fungal strains, but also by analyzing their molecular targets in the cell. 


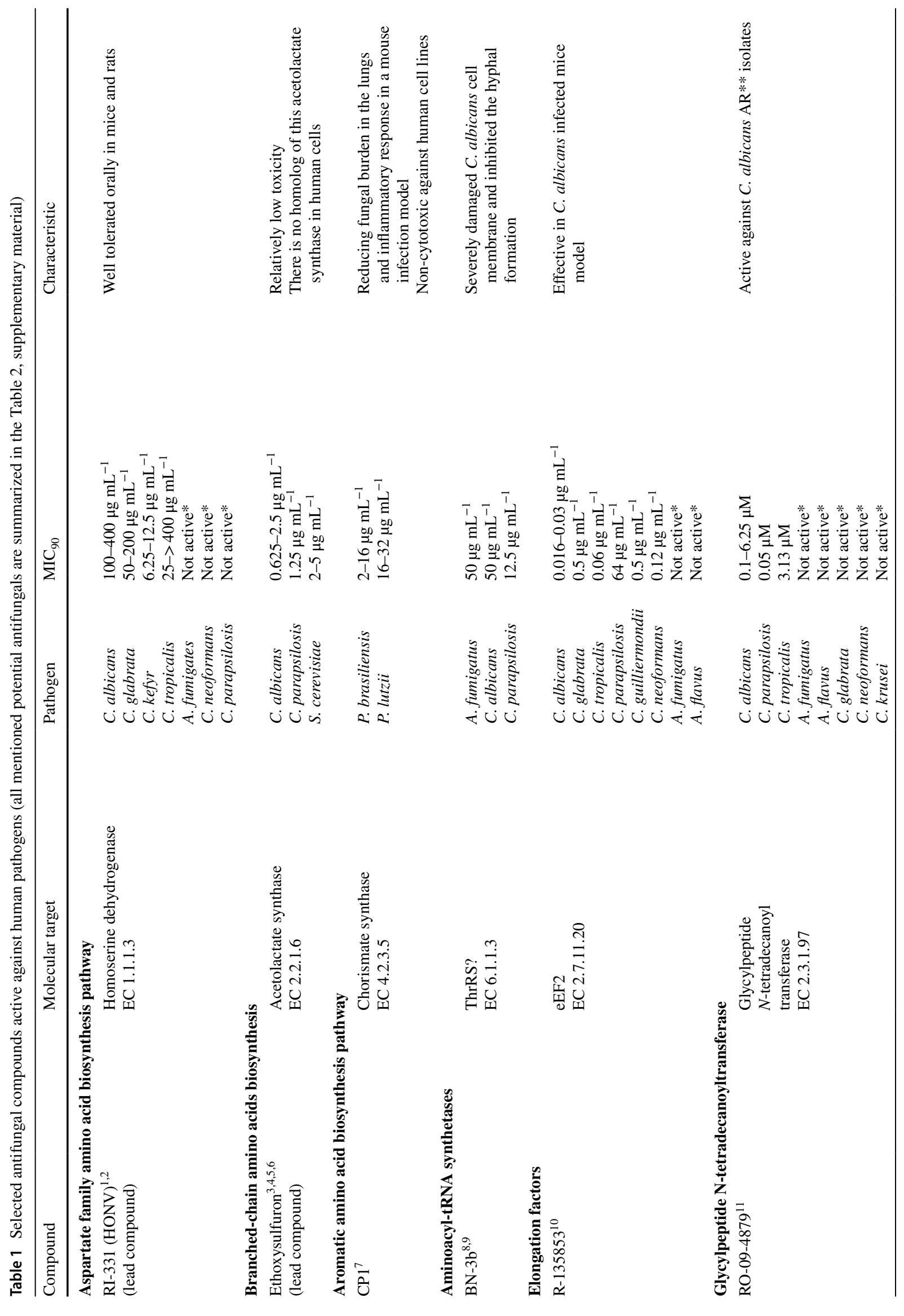




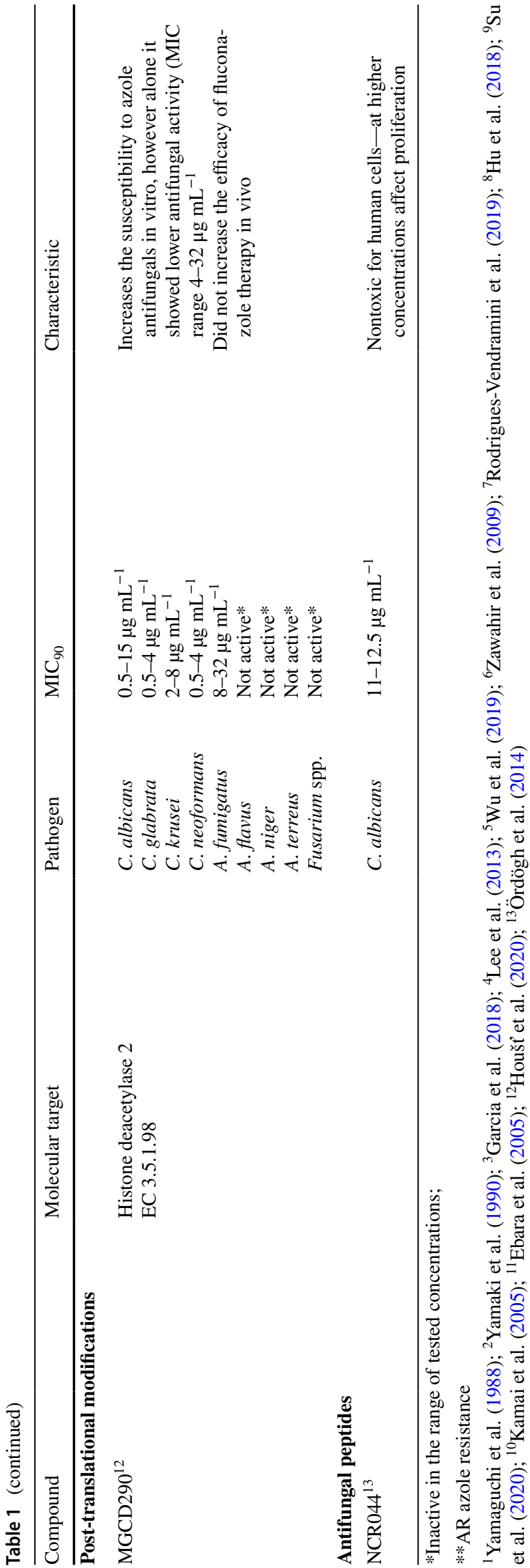

We presented research on deletion mutants, their viability, virulence, and the ability to create biofilm. The structures of the described compounds are often based on research conducted in previous years, therefore, we considered it necessary to present the results on these lead compounds. Many enzymatic inhibitors presented in this review exhibit broad-spectrum antifungal activity, MIC values better than commonly used antifungal drugs, low, if any, cytotoxicity against human/mammalian cells and activity against azoleresistant strains. Activity of some has been proven in the infected animal model. Although none of them have yet been accepted for clinical use, efforts are being made to improve their properties or to find novel compounds that satisfy the clinical requirements. The fact that most of them have been presented in recent years clearly indicates that the potential for their further expansion is apparently emerging.

Could blocking the enzymes involved in amino acid biosynthesis, protein biosynthesis and post-translational modification pathways be an effective strategy in antifungal therapy?

Using enzymes involved in the amino acid biosynthetic pathway as molecular targets in antifungal therapy is controversial; in some cases, auxotrophs can take the missing amino acid from the environment, eliminating the negative effects resulting from blocking the functioning of enzymes. During the infection, specific niches with different content of amino acids or nitrogen sources are penetrated, which may affect the effectiveness of the compound depending on the site of infection. Moreover, fungi can secrete proteases that enable them to release an amino acid from the host protein. However, these are just some assumptions that would need to be confronted with a particular fungal strain and a molecular target. In our opinion, compounds whose molecular targets are enzymes participating in the pathways described in this review show great potential. First, because sufficient number of studies show that the enzymes involved in these pathways are essential for fungi vitality and virulence. Disrupted mutants exhibit a defect in hyphal morphogenesis, biofilm growth, higher sensitivity to antifungals, and reduced virulence in animalinfected model, which may be related to the second point; because during infection, the microorganism's need for amino acids increases due to specific fungal processes like: morphological transition, adhesion, the formation of biofilms, phenotypic switching, stress response machineries associated with the overproduction of numerous proteins. And third, significant differences in the structure and functioning between fungal enzymes and relevant enzymes in the human body give hope for the development of a selective antifungal inhibitor, which simultaneously increases the likelihood of obtaining a low-toxic drug. These considerations are confirmed by the low toxicity to human/ mammalian cells of the presented compounds. 
Supplementary Information The online version contains supplementary material available at https://doi.org/10.1007/s00726-021-03007-6.

Acknowledgements The authors would like to thank Professor Sławomir Milewski from the Gdansk University of Technology for the constructive feedback.

Author contributions $\mathrm{KR}$ and AK contributed to the conception of the article. KR and AK find the relevant literature. AK interpreting the literature and wrote the first draft of the manuscript. KR revised it critically for important content. AK prepared the figures. KR wrote sections of the manuscript. KR and AK contributed to manuscript revision, read, and approved the submitted version. Both authors contributed equally to the manuscript.

Funding This research did not receive any specific grant from funding agencies in the public, commercial, or not-for-profit sectors.

\section{Availability of data and materials Not applicable.}

\section{Declarations}

Conflict of interest The authors declare that the research was conducted in the absence of any commercial or financial relationships that could be construed as a potential conflict of interest.

Ethics approval The manuscript does not contain clinical studies or patient data.

Open Access This article is licensed under a Creative Commons Attribution 4.0 International License, which permits use, sharing, adaptation, distribution and reproduction in any medium or format, as long as you give appropriate credit to the original author(s) and the source, provide a link to the Creative Commons licence, and indicate if changes were made. The images or other third party material in this article are included in the article's Creative Commons licence, unless indicated otherwise in a credit line to the material. If material is not included in the article's Creative Commons licence and your intended use is not permitted by statutory regulation or exceeds the permitted use, you will need to obtain permission directly from the copyright holder. To view a copy of this licence, visit http://creativecommons.org/licenses/by/4.0/.

\section{References}

Abastabar M, Haghani I, Shokohi T, Hedayati MT, Aghili SR, Jedi A et al (2018) Low in vitro antifungal activity of tavaborole against yeasts and molds from onychomycosis. Antimicrob Agents $\mathrm{Ch}$ 62:e01632-e1718. https://doi.org/10.1128/AAC.01632-18

Amich J, Dümig M, O’Keeffe G, Binder J, Doyle S, Beilhack A et al (2016) Exploration of sulfur assimilation of Aspergillus fumigatus reveals biosynthesis of sulfur-containing amino acids as a virulence determinant. Infect Immun 84:917-929. https://doi.org/ 10.1128/IAI.01124-15

Aoki Y, Kamiyama T, Fujii T, Yamamoto M, Ohwada J, Arisawa M et al (1995) Design of an antifungal methionine inhibitor not antagonized by methionine. Biol Pharm Bull 18:1267-1271. https://doi.org/10.1248/bpb.18.1267

Arévalo-Rodríguez M, Pan X, Boeke JD, Heitman J (2004) FKBP12 controls aspartate pathway flux in Saccharomyces cerevisiae to prevent toxic intermediate accumulation. Eukaryot Cell 3:12871296. https://doi.org/10.1128/EC.3.5.1287-1296.2004

Azevedo MM, Faria-Ramos I, Cruz LC, Pina-Vaz C, Gonçalves Rodrigues A (2015) Genesis of azole antifungal esistance from agriculture to clinical settings. J Agr Food Chem 63:7463-7468. https://doi.org/10.1021/acs.jafc.5b02728

Bae NS, Seberg AP, Carroll LP, Swanson MJ (2017) Identification of genes in Saccharomyces cerevisiae that are haploinsufficient for overcoming amino acid starvation. G3 Genes Genom Genet 7:1061-1084. https://doi.org/10.1534/g3.116.037416

Bagatin MC, Rozada AMF, Rodrigues FAV, Bueno PSA, Santos JL, Canduri F et al (2019) New 4-methoxy-naphthalene derivatives as promisor antifungal agents for paracoccidioidomycosis treatment. Future Microbiol 14:235-245. https://doi.org/10.2217/ fmb-2018-0276

Becker JM, Kauffman SJ, Hauser M, Huang L, Lin M, Sillaots S et al (2010) Pathway analysis of Candida albicans survival and virulence determinants in a murine infection model. Proc Natl Acad Sci USA 107:22044-22049. https://doi.org/10.1073/pnas.10098 45107

Berg JM, Tymoczko JL, Gatto GJ Jr, Stryer L (2015) Protein synthesis. In: Schultz L, Pech I (eds) Biochemistry, 8th edn. WH Freeman \& Co, New York, pp 893-924

Boman HG, Agerberth B, Boman A (1993) Mechanisms of action on Escherichia coli of cecropin P1 and PR-39, two antibacterial peptides from pig intestine. Infect Immun 61:2978-2984. https:// doi.org/10.1128/iai.61.7.2978-2984.1993

Bongomin F, Gago S, Oladele RO, Denning DW (2017) Global and multi-national prevalence of fungal diseases - estimate precision. J Fungi 3:57. https://doi.org/10.3390/jof3040057

Braus GH (1991) Aromatic amino acid biosynthesis in the yeast Saccharomyces cerevisiae: a model system for the regulation of a eukaryotic biosynthetic pathway. Microbiol Mol Biol R 55:349370. https://doi.org/10.1128/mmbr.55.3.349-370.1991

Brown GD, Denning DW, Gow NAR, Levitz SM, Netea MG, White TC (2012) Hidden killers: human fungal infections. Sci Transl Med 4:1-10. https://doi.org/10.1126/scitranslmed.3004404

Brunke S, Seider K, Almeida RS, Heyken A, Fleck CB, Brock M et al (2010) Candida glabrata tryptophan-based pigment production via the Ehrlich pathway. Mol Microbiol 76:25-47. https://doi. org/10.1111/j.1365-2958.2010.07052.x

Brzywczy J, Paszewski A (1993) Role of O-acetylhomoserine sulfhydrylase in sulfur amino acid synthesis in various yeasts. Yeast 9:1335-1342. https://doi.org/10.1002/yea.320091207

Bueno PSA, Rodrigues-Vendramini FAV, Toplak M, Macheroux P, Kioshima ÉS, Seixas FAV (2019a) New inhibitors of chorismate synthase present antifungal activity against Paracoccidioides brasiliensis. Future Microbiol 14:969-980. https://doi.org/10. 2217/fmb-2019-0052

Bueno PSA, Rodrigues FAV, Santos JL, Canduri F, Biavatti DC, Pimentel AL et al (2019b) New inhibitors of homoserine dehydrogenase from Paracoccidioides brasiliensis presenting antifungal activity. J Mol Model 25:325. https://doi.org/10.1007/ s00894-019-4221-2

Caspi R, Billington R, Fulcher CA, Keseler IM, Kothari A, Krummenacker M et al (2018) The MetaCyc database of metabolic pathways and enzymes. Nucleic Acids Res 46:D633-D639. https:// doi.org/10.1093/nar/gkx935

Castle M, Nazarian A, Yi SS, Tempst P (1999) Lethal effects of apidaecin on Escherichia coli involve sequential molecular interactions with diverse targets. J Biol Chem 274:32555-32564. https://doi. org/10.1074/jbc. 274.46 .32555

Chakraborty B, Mukherjee R, Sengupta J (2013) Structural insights into the mechanism of translational inhibition by the fungicide sordarin. J Comput Aid Mol Des 27:173-184. https://doi.org/10. 1007/s10822-013-9636-8 
Chakraborty B, Sejpal NV, Payghan PV, Ghoshal N, Sengupta J (2016) Structure-based designing of sordarin derivative as potential fungicide with pan-fungal activity. J Mol Graph Model 66:133-142. https://doi.org/10.1016/j.jmgm.2016.03.013

Chaton CT, Rodriguez ES, Reed RW, Li J, Kenner CW, Korotkov KV (2019) Structural analysis of mycobacterial homoserine transacetylases central to methionine biosynthesis reveals druggable active site. Sci Rep-UK 9:1-11. https://doi.org/10.1038/ s41598-019-56722-2

Chen KC, Lin CY, Chung MC et al (2002) Cloning and characterization of a cDNA encoding an antimicrobial protein from mung bean seeds. Bot Bull Acad Sin 43:251-259. https://doi.org/10.7016/ BBAS.200210.0251

Chen G-H, Hsu M-P, Tan C-H et al (2005) Cloning and characterization of a plant defensin VaD1 from azuki bean. J Agric Food Chem 53:982-988. https://doi.org/10.1021/jf0402227

Chen C, Yan Q, Tao M, Shi H, Han X, Jia L et al (2019a) Characterization of serine acetyltransferase (CysE) from methicillinresistant Staphylococcus aureus and inhibitory effect of two natural products on CysE. Microb Pathogenesis 131:218-226. https://doi.org/10.1016/j.micpath.2019.04.002

Chen W, Li Y, Zhou Y, Ma Y, Li Z (2019b) Design, synthesis and SAR study of novel sulfonylurea derivatives containing arylpyrimidine moieties as potential anti-phytopathogenic fungal agents. Chin Chem Lett 30:2160-2162. https://doi.org/10. 1016/j.cclet.2019.04.072

Chimenti F, Bizzarri B, Maccioni E, Secci D, Bolasco A, Chimenti P et al (2009) A novel histone acetyltransferase inhibitor modulating Gcn5 network: cyclopentylidene-[4-(4'-chlorophenyl) thiazol-2-yl)hydrazone. J Med Chem 52:530-536. https://doi. org/10.1021/jm800885d

Choudhary P, Chakdar H, Singh A, Kumar S, Singh SK, Aarthy M et al (2020) Computational identification and antifungal bioassay reveals phytosterols as potential inhibitor of Alternaria arborescens. J Biomol Struct Dyn 38:1143-1157. https://doi. org/10.1080/07391102.2019.1597767

Colilla FJ, Rocher A, Mendez E (1990) $\gamma$-Purothionins: amino acid sequence of two polypeptides of a new family of thionins from wheat endosperm. FEBS Lett 270:191-194. https://doi.org/10. 1016/0014-5793(90)81265-P

Coronado D, Merchant T, Chanda S, Zane L (2015) In vitro nail penetration and antifungal activity of tavaborole, a boron-based pharmaceutical. J Drugs Dermatol 14:609-614

Dahal GP, Viola RE (2018a) Structural insights into inhibitor binding to a fungal ortholog of aspartate semialdehyde dehydrogenase. Biochem Bioph Res Co 503:2848-2854. https://doi.org/ 10.1016/j.bbrc.2018.08.053

Dahal GP, Viola RE (2018b) A fragment library screening approach to identify selective inhibitors against an essential fungal enzyme. SLAS Discov 23:520-531. https://doi.org/10.1177/ 2472555218767844

de Oliveira CA, Moreira Gomes V (2012) Plant defensins and defensin-like peptides-biological activities and biotechnological applications. Curr Pharm Des 17:4270-4293. https://doi.org/ 10.2174/138161211798999447

de Melo AT, Martho KF, Roberto TN, Nishiduka ES, Machado J, Brustolini OJB et al (2019) The regulation of the sulfur amino acid biosynthetic pathway in Cryptococcus neoformans: the relationship of Cys3, Calcineurin, and Gpp2 phosphatases. Sci Rep-UK 9:11923. https://doi.org/10.1038/s41598-019-48433-5

Dean N (1995) Yeast glycosylation mutants are sensitive to aminoglycosides. Proc Natl Acad Sci USA 92:1287-1291. https:// doi.org/10.1073/pnas.92.5.1287

Deshpande AA, Bhatia M, Laxman S, Bachhawat AK (2017) Thiol trapping and metabolic redistribution of sulfur metabolites enable cells to overcome cysteine overload. Microb Cell 4:112-126. https://doi.org/10.15698/mic2017.04.567

Dever TE, Kinzy TG, Pavitt GD (2016) Mechanism and regulation of protein synthesis in Saccharomyces cerevisiae. Genetics 203:65-107. https://doi.org/10.1534/genetics.115.186221

Di Santo R (2008) Recent patents in antifungal agent discovery. Expert Opin Ther Pat 18:275-292. https://doi.org/10.1517/ 13543776.18.3.275

Ding N, Jiang Y, Han L, Chen X, Ma J, Qu X et al (2016) Bafilomycins and odoriferous sesquiterpenoids from Streptomyces albolongus isolated from Elephas maximus feces. J Nat Prod 79:799-805. https://doi.org/10.1021/acs.jnatprod.5b00827

Do E, Hu G, Oliveira D, Kronstad JW, Jung WH, Laboratories MS et al (2016) Virulence in Cryptococcus neoformans. Fungal Genet Biol 75:11-19. https://doi.org/10.1016/j.fgb.2014.12.006

Dörfer M, Heine D, König S, Gore S, Werz O, Hertweck C et al (2019) Melleolides impact fungal translation: via elongation factor 2. Org Biomol Chem 17:4906-4916. https://doi.org/10. 1039/c9ob00562e

Duncan K, Edwards RM, Coggins JR (1988) The Saccharomyces cerevisiae $A R O 1$ gene An example of the co-ordinate regulation of five enzymes on a single biosynthetic pathway. FEBS Lett 241:83-88. https://doi.org/10.1016/0014-5793(88)81036-6

Ebanks RO, Chisholm K, McKinnon S, Whiteway M, Pinto DM (2006) Proteomic analysis of Candida albicans yeast and hyphal cell wall and associated proteins. Proteomics 6:21472156. https://doi.org/10.1002/pmic. 200500100

Ebara S, Naito H, Nakazawa K, Ishii F, Nakamura M (2005) FTR1335 is a novel synthetic inhibitor of Candida albicans $\mathrm{N}$-myristoyltransferase with fungicidal activity. Biol Pharm Bull 28:591-595. https://doi.org/10.1248/bpb.28.591

Ejim L, Mirza IA, Capone C, Nazi I, Jenkins S, Chee GL et al (2004) New phenolic inhibitors of yeast homoserine dehydrogenase. Bioorgan Med Chem 12:3825-3830. https://doi.org/10.1016/j. bmc.2004.05.009

Fang W, Robinson DA, Raimi OG, Blair DE, Harrison JR, Lockhart DEA et al (2015) N-Myristoyltransferase is a cell wall target in Aspergillus fumigatus. ACS Chem Biol 10:1425-1434. https:// doi.org/10.1021/cb5008647

Fernandes JDS, Martho K, Tofik V, Vallim MA, Pascon RC (2015) The role of amino acid permeases and tryptophan biosynthesis in Cryptococcus neoformans survival. PLoS ONE 10:1-22. https://doi.org/10.1371/journal.pone.0132369

Fernández de Ullivarri M, Arbulu S, Garcia-Gutierrez E, Cotter PD (2020) Antifungal peptides as therapeutic agents. Front Cell Infect Microbiol 10:105

Galán JE, Nakayama K, Curtiss R (1990) Cloning and characterization of the asd gene of Salmonella typhimurium: use in stable maintenance of recombinant plasmids in Salmonella vaccine strains. Gene 94:29-35. https://doi.org/10.1016/0378-1119(90) 90464-3

Gao YM, Wang XJ, Zhang J, Li M, Liu CX, An J et al (2012) Borrelidin, a potent antifungal agent: insight into the antifungal mechanism against Phytophthora sojae. J Agric Food Chem 60:9874-9881. https://doi.org/10.1021/jf302857x

Garcia MD, Chua SMH, Low YS, Lee YT, Agnew-Francis K, Wang JG et al (2018) Commercial AHAS-inhibiting herbicides are promising drug leads for the treatment of human fungal pathogenic infections. Proc Natl Acad Sci USA 115:E9649-E9658. https:// doi.org/10.1073/pnas.1809422115

Gintjee TJ, Donnelley MA, Thompson GR (2020) Aspiring antifungals: review of current antifungal pipeline developments. J Fungi 6:28. https://doi.org/10.3390/jof6010028

Gophna U, Bapteste E, Doolittle WF, Biran D, Ron EZ (2005) Evolutionary plasticity of methionine biosynthesis. Gene 355:48-57. https://doi.org/10.1016/j.gene.2005.05.028 
Gray KC, Palacios DS, Dailey I, Endo MM, Uno BE, Wilcock BC et al (2012) Amphotericin primarily kills yeast by simply binding ergosterol. Proc Natl Acad Sci USA 109:2234-2239. https://doi. org/10.1073/pnas.1117280109

Gualco L, Debbia EA, Bandettini R, Pescetto L, Cavallero A, Ossi MC et al (2007) Antifungal resistance in Candida spp. isolated in Italy between 2002 and 2005 from children and adults. Int J Antimicrob Ag 29:179-184. https://doi.org/10.1016/j.ijantimicag.2006.08.047

Gupta AK, Versteeg SG (2016) Tavaborole-a treatment for onychomycosis of the toenails. Expert Rev Clin Phar 9:1145-1152. https://doi.org/10.1080/17512433.2016.1206467

Haidar G, Singh N (2018) How we approach combination antifungal therapy for invasive aspergillosis and mucormycosis in transplant recipients. Transplantation 102:1815-1823. https://doi. org/10.1097/TP.0000000000002353

Han M, Xie M, Han J, Yuan D, Yang T, Xie Y (2018) Development and validation of a rapid, selective, and sensitive LC-MS/MS method for simultaneous determination of $\mathrm{d}$ - and 1-amino acids in human serum: application to the study of hepatocellular carcinoma. Anal Bioanal Chem 410:2517-2531. https://doi. org/10.1007/s00216-018-0883-3

Han G, Liu N, Li C, Tu J, Li Z, Sheng C (2020) Discovery of novel fungal lanosterol $14 \alpha$-demethylase (CYP51)/histone deacetylase dual inhibitors to treat azole-resistant candidiasis. J Med Chem 63:5341-5359. https://doi.org/10.1021/acs.jmedchem. 0c00102

Hansen J, Johannesen PF (2000) Cysteine is essential for transcriptional regulation of the sulfur assimilation genes in Saccharomyces cerevisiae. Mol Gen Genet 263:535-542. https://doi.org/ 10.1007/s004380051199

Harb OS, Kwaik YA (1998) Identification of the aspartate- $\beta$ semialdehyde dehydrogenase gene of Legionella pneumophila and characterization of a null mutant. Infect Immun 66:18981903. https://doi.org/10.1128/iai.66.5.1898-1903.1998

Havlickova B, Czaika VA, Friedrich M (2008) Epidemiological trends in skin mycoses worldwide. Mycoses 51:2-15. https://doi.org/ 10.1111/j.1439-0507.2008.01606.x

Healy CE, Heydens WF, Naylor MW (2004) Mammalian toxicology overview and human risk assessment for sulfosulfuron. Regul Toxicol Pharmacol 39:310-324. https://doi.org/10.1016/j.yrtph. 2004.02.005

Hébert A, Casaregola S, Beckerich JM (2011) Biodiversity in sulfur metabolism in hemiascomycetous yeasts. FEMS Yeast Res 11:366-378. https://doi.org/10.1111/j.1567-1364.2011.00725.x

Hediger ME (2004) Design, synthesis, and evaluation of aza inhibitors of chorismate mutase. Bioorgan Med Chem 12:4995-5010. https://doi.org/10.1016/j.bmc.2004.06.037

Hou YP, Mao XW, Qu XP et al (2018) Molecular and biological characterization of Sclerotinia sclerotiorum resistant to the anilinopyrimidine fungicide cyprodinil. Pestic Biochem Phys 146:80-89. https://doi.org/10.1016/j.pestbp.2018.03.001

Houše J, Spížek J, Havlíček V (2020) Antifungal Drugs. Metabolites 10:106. https://doi.org/10.3390/metabo10030106

Howard SJ, Cerar D, Anderson MJ, Albarrag A, Fisher MC, Pasqualotto AC et al (2009) Frequency and evolution of azole resistance in Aspergillus fumigatus associated with treatment failure. Emerg Infect Dis 15:1068-1076. https://doi.org/10.3201/eid15 07.090043

Hu QH, Liu RJ, Fang ZP, Zhang J, Ding YY, Tan M et al (2013) Discovery of a potent benzoxaborole-based anti-pneumococcal agent targeting leucyl-tRNA synthetase. Sci Rep-UK 3:2475. https:// doi.org/10.1038/srep02475

Hu C, Su H, Luo J, Han L, Liu Q, Wu W et al (2018) Design, synthesis and antifungal evaluation of borrelidin derivatives. Bioorgan
Med Chem 26:6035-6049. https://doi.org/10.1016/j.bmc.2018. 11.005

Huang M-E, Facca C, Fatmi Z, Baïlle D, Bénakli S, Vernis L (2016) DNA replication inhibitor hydroxyurea alters Fe-S centers by producing reactive oxygen species in vivo. Sci Rep-UK 6:29361. https://doi.org/10.1038/srep29361

Jacques SL, Mirza IA, Ejim L, Koteva K, Hughes DW, Green K et al (2003) Enzyme-assisted suicide: molecular basis for the antifungal activity of 5-hydroxy-4-oxonorvaline by potent inhibition of homoserine dehydrogenase. Chem Biol 10:989-995. https://doi. org/10.1016/j.chembiol.2003.09.015

Jafari-Nodoushan AA, Kazemi AH, Mirzaii F, Dehghani M (2008) Fluconazole susceptibility profile of Candida isolates recovered from patients specimens admitted to Yazd central laboratory. Iran J Pharm Res 7:69-75. https://doi.org/10.22037/ijpr.2010.746

Joshi P, Gupta A, Gupta V (2019) Insights into multifaceted activities of CysK for therapeutic interventions. 3 Biotech 9:44. https://doi. org/10.1007/s13205-019-1572-4

Kamai Y, Kakuta M, Shibayama T, Fukuoka T, Kuwahara S (2005) Antifungal activities of R-135853, a sordarin derivative, in experimental candidiasis in mice. Antimicrob Agents Ch 49:5256. https://doi.org/10.1128/AAC.49.1.52-56.2005

Khedr MA, Massarotti A, Mohamed ME (2018) Rational discovery of $(+)(\mathrm{S})$ abscisic acid as a potential antifungal agent: a repurposing approach. Sci Rep-UK 8:1-14. https://doi.org/10.1038/ s41598-018-26998-x

Kingsbury JM, McCusker JH (2008) Threonine biosynthetic genes are essential in Cryptococcus neoformans. Microbiology 154:27672775. https://doi.org/10.1099/MIC.0.2008/019729-0

Kingsbury JM, McCusker JH (2010c) Cytocidal amino acid starvation of Saccharomyces cerevisiae and Candida albicans acetolactate synthase (ilv2 2 ) mutants is influenced by the carbon source and rapamycin. Microbiology 156:929-939. https://doi.org/10.1099/ mic.0.034348-0

Kingsbury JM, McCusker JH (2010a) Fungal homoserine kinase (thrls) mutants are attenuated in virulence and die rapidly upon threonine starvation and serum incubation. Eukaryot Cell 9:729737. https://doi.org/10.1128/EC.00045-10

Kingsbury JM, McCusker JH (2010b) Homoserine toxicity in Saccharomyces cerevisiae and Candida albicans homoserine kinase (thrla) mutants. Eukaryot Cell 9:717-728. https://doi.org/10. 1128/EC.00044-10

Kingsbury JM, Yang Z, Ganous TM et al (2004) Cryptococcus neoformans Ilv2p confers resistance to sulfometuron methyl and is required for survival at $37{ }^{\circ} \mathrm{C}$ and in vivo. Microbiology 150:1547-1558. https://doi.org/10.1099/mic.0.26928-0

Kingsbury JM, Goldstein AL, McCusker JH (2006) Role of nitrogen and carbon transport, regulation, and metabolism genes for Saccharomyces cerevisiae survival in vivo. Eukaryot Cell 5:816824. https://doi.org/10.1128/EC.5.5.816-824.2006

Kohlhaw GB (2003) Leucine biosynthesis in fungi: entering metabolism through the back door. Microbiol Mol Biol R 67:1-15. https://doi.org/10.1128/mmbr.67.1.1-15.2003

Kuchler K, Jenull S, Shivarathri R, Chauhan N (2016) Fungal KATs/ KDACs: a new highway to better antifungal drugs? PLoS Pathog 12:e1005938. https://doi.org/10.1371/journal.ppat.1005938

Kugler M, Loeffler W, Rapp C, Kern A, Jung G (1990) Rhizocticin A, an antifungal phosphono-oligopeptide of Bacillus subtilis ATCC 6633: biological properties. Arch Microbiol 153:276-281. https://doi.org/10.1007/BF00249082

Kulikova VV, Revtovich SV, Bazhulina NP, Anufrieva NV, Kotlov MI, Koval VS et al (2019) Identification of O-acetylhomoserine sulfhydrylase, a putative enzyme responsible for methionine biosynthesis in Clostridioides difficile: gene cloning and biochemical characterizations. IUBMB Life 71:1815-1823. https://doi.org/ 10.1002/iub.2139 
Kumar A, John L, Alam MM, Gupta A, Sharma G, Pillai B et al (2006) Homocysteine- and cysteine-mediated growth defect is not associated with induction of oxidative stress response genes in yeast. Biochem J 396:61-69. https://doi.org/10.1042/BJ20051411

Lee YT, Cui CJ, Chow EW, Pue N, Lonhienne T, Wang JG et al (2013) Sulfonylureas have antifungal activity and are potent inhibitors of Candida albicans acetohydroxyacid synthase. J Med Chem 56:210-219. https://doi.org/10.1021/jm301501k

Lee YT, Fang YY, Sun YW, Hsu HC, Weng SM, Tseng TL et al (2018) THR1 mediates GCN4 and CDC4 to link morphogenesis with nutrient sensing and the stress response in Candida albicans. Int J Mol Med 42:3193-3208. https://doi.org/10.3892/ijmm.2018. 3930

Liang Z, Xu H, Tian Y, Guo M, Su X, Guo C (2016) Design, synthesis and antifungal activity of novel benzofuran-triazole hybrids. Molecules 21:732. https://doi.org/10.3390/molecules21060732

Lin G, Bai X, Duan W, Cen B, Huang M, Lu S (2019) High valueadded application of sustainable natural forest product $\alpha$-pinene: synthesis of myrtenal oxime esters as potential KARI inhibitors. ACS Sustain Chem Eng 7:7862-7868. https://doi.org/10.1021/ acssuschemeng.9b00254

Liu X, Han Q, Xu J, Wang J, Shi J (2015) Acetohydroxyacid synthase FgIlv2 and FgIlv6 are involved in BCAA biosynthesis, mycelial and conidial morphogenesis, and full virulence in Fusarium graminearum. Sci Rep-UK 5:1-14. https://doi.org/10.1038/srep1 6315

Liu N, Tu J, Dong G, Wang Y, Sheng C (2018) Emerging new targets for the treatment of resistant fungal infections. J Med Chem 61:5484-5511. https://doi.org/10.1021/acs.jmedchem.7b01413

Liu X, Jiang Y, Zhang Y, Yu M, Jiang H, Xu J et al (2019) FgIlv3a is crucial in branched-chain amino acid biosynthesis, vegetative differentiation, and virulence in Fusarium graminearum. J Microbiol 57:694-703. https://doi.org/10.1007/s12275-019-9123-6

Lodge JK, Jackson-Machelski E, Toffaletti DL, Perfect JR, Gordon JI (1994) Targeted gene replacement demonstrates that myristoylCoA:protein $\mathrm{N}$-myristoyltransferase is essential for viability of Cryptococcus neoformans. Proc Natl Acad Sci USA 91:1200812012. https://doi.org/10.1073/pnas.91.25.12008

López G, Quezada H, Duhne M, González J, Lezama M, El-Hafidi M et al (2015) Diversification of paralogous $\alpha$-isopropylmalate synthases by modulation of feedback control and hetero-oligomerization in Saccharomyces cerevisiae. Eukaryot Cell 14:564-577. https://doi.org/10.1128/EC.00033-15

Lumb M, Macey PE, Spyvee J, Whitmarsh JM, Wright RD (1965) Isolation of vivomycin and borrelidin, two antibiotics with antiviral activity, from a species of Streptomyces (C2989). Nature 206:263-265. https://doi.org/10.1038/206263a0

Ma B, Shen J, Yindeeyoungyeon W, Ruan Y (2017) A novel antibiotic mechanism of L-cyclopropylalanine blocking the biosynthetic pathway of essential amino acid L-leucine. Molecules 22:2224. https://doi.org/10.3390/molecules22122224

Magalhães J, Franko N, Raboni S, Annunziato G, Tammela P, Bruno $A$ et al (2020) Inhibition of nonessential bacterial targets: discovery of a novel serine O-acetyltransferase inhibitor. ACS Med Chem Lett 11:790-797. https://doi.org/10.1021/acsmedchemlett. $9 \mathrm{~b} 00627$

Manhas R, Tandon S, Sen SS, Tiwari N, Munde M, Madhubala R (2018) Leishmania donovani parasites are inhibited by the benzoxaborole AN2690 targeting leucyl-tRNA synthetase. Antimicrob Agents Ch 62:e00079-e118. https://doi.org/10.1128/AAC. 00079-18

Markham A (2014) Tavaborole: first global approval. Drugs 74:15551558. https://doi.org/10.1007/s40265-014-0276-7

Martínez-Gomariz M, Perumal P, Mekala S, Nombela C, Chaffin WLJ, Gil C (2009) Proteomic analysis of cytoplasmic and surface proteins from yeast cells, hyphae, and biofilms of Candida albicans.
Proteomics 9:2230-2252. https://doi.org/10.1002/pmic.20070 0594

Masubuchi M, Ebiike H, Kawasaki KI, Sogabe S, Morikami K, Shiratori Y et al (2003) Synthesis and biological activities of benzofuran antifungal agents targeting fungal $\mathrm{N}$-myristoyltransferase. Bioorgan Med Chem 11:4463-4478. https://doi.org/10.1016/ S0968-0896(03)00429-2

McCarthy MW, Walsh TJ (2018) Amino acid metabolism and transport mechanisms as potential antifungal targets. Int J Mol Sci 19:909. https://doi.org/10.3390/ijms19030909

McCune CD, Chan SJ, Beio ML, Shen W, Chung WJ, Szczesniak LM et al (2016) Zipped synthesis by cross-metathesis provides a cystathionine $\beta$-synthase inhibitor that attenuates cellular $\mathrm{H} 2 \mathrm{~S}$ levels and reduces neuronal infarction in a rat ischemic stroke model. ACS Cent Sci 2:242-252. https://doi.org/10. 1021/acscentsci.6b00019

Meir Z, Osherov N (2018) Vitamin biosynthesis as an antifungal target. J Fungi 4:72. https://doi.org/10.3390/jof4020072

Méndez E, Rocher A, Calero M et al (1996) Primary structure of $\omega$-hordothionin, a member of a novel family of thionins from barley endosperm, and its inhibition of protein synthesis in eukaryotic and prokaryotic cell-free systems. Eur J Biochem 239:67-73. https://doi.org/10.1111/j.1432-1033.1996.0067u.x

Mir R, Jallu S, Singh TP (2015) The shikimate pathway: review of amino acid sequence, function and three-dimensional structures of the enzymes. Crit Rev Microbiol 41:172-189. https:// doi.org/10.3109/1040841X.2013.813901

Nazi I, Scott A, Sham A, Rossi L, Williamson PR, Kronstad JW et al (2007) Role of homoserine transacetylase as a new target for antifungal agents. Antimicrob Agents Ch 51:1731-1736. https://doi.org/10.1128/AAC.01400-06

O'Meara TR, Veri AO, Ketela T, Jiang B, Roemer T, Cowen LE (2015) Global analysis of fungal morphology exposes mechanisms of host cell escape. Nat Commun 6:6741. https://doi.org/ 10.1038/ncomms 7741

Obando Montoya EJ, Mélin C, Blanc N, Lanoue A, Foureau E, Boudesocque L et al (2014) Disrupting the methionine biosynthetic pathway in Candida guilliermondii: characterization of the MET2 gene as counter-selectable marker. Yeast 31:243251. https://doi.org/10.1002/yea.3012

Oki T, Hirano M, Tomatsu K, Numata K-I, Kamei H (1989) Cispentacin, a new antifungal antibiotic. II. In vitro and in vivo antifungal activities. J Antibiot 42:1756-1762. https://doi.org/10. 7164/antibiotics.42.1756

Orasch T, Dietl AM, Shadkchan Y, Binder U, Bauer I, Lass-Flörl C et al (2019) The leucine biosynthetic pathway is crucial for adaptation to iron starvation and virulence in Aspergillus fumigatus. Virulence 10:925-934. https://doi.org/10.1080/ 21505594.2019.1682760

Ördögh L, Vörös A, Nagy I et al (2014) Symbiotic plant peptides eliminate Candida albicans both in vitro and in an epithelial infection model and inhibit the proliferation of immortalized human cells. Biomed Res Int 2014:1-9. https://doi.org/10. 1155/2014/320796

Osborn RW, De Samblanx GW, Thevissen K et al (1995) Isolation and characterisation of plant defensins from seeds of Asteraceae, Fabaceae, Hippocastanaceae and Saxifragaceae. FEBS Lett 368:257-262. https://doi.org/10.1016/0014-5793(95)00666-W

Pascon RC, Ganous TM, Kingsbury JM, Cox GM, McCusker JH (2004) Cryptococcus neoformans methionine synthase: expression analysis and requirement for virulence. Microbiology 150:3013-3023. https://doi.org/10.1099/mic.0.27235-0

Patrzykat A, Friedrich CL, Zhang L et al (2002) Sublethal concentrations of pleurocidin-derived antimicrobial peptides inhibit macromolecular synthesis in Escherichia coli. Antimicrob Agents 
Chemother 46:605-614. https://doi.org/10.1128/AAC.46.3. 605-614.2002

Pérez E, Belén Rubio M, Cardoza RE, Gutiérrez S, Bettiol W, Monte E et al (2015) The importance of chorismate mutase in the biocontrol potential of Trichoderma parareesei. Front Microbiol 6:1-14. https://doi.org/10.3389/fmicb.2015.01181

Pfaller MA, Messer SA, Georgopapadakou N, Martell LA, Besterman JM, Diekema DJ (2009) Activity of MGCD290, a Hos2 histone deacetylase inhibitor, in combination with azole antifungals against opportunistic fungal pathogens. J Clin Microbiol 47:3797-3804. https://doi.org/10.1128/JCM.00618-09

Pfaller MA, Rhomberg PR, Messer SA, Castanheira M (2015) In vitro activity of a Hos2 deacetylase inhibitor, MGCD290, in combination with echinocandins against echinocandin-resistant Candida species. Diagn Micr Infec Dis 81:259-263. https:// doi.org/10.1016/j.diagmicrobio.2014.11.008

Poyraz Ö, Jeankumar VU, Saxena S, Schnell R, Haraldsson M, Yogeeswari P et al (2013) Structure-guided design of novel thiazolidine inhibitors of O-acetyl serine sulfhydrylase from Mycobacterium tuberculosis. J Med Chem 56:6457-6466. https://doi.org/10.1021/jm400710k

Quindós G, Gil-Alonso S, Marcos-Arias C, Sevillano E, Mateo E, Jauregizar $N$ et al (2019) Therapeutic tools for oral candidiasis: Current and new antifungal drugs. Med Oral Patol Oral Cir Bucal 24:e172-e180. https://doi.org/10.4317/medoral.22978

Regueiro-Ren A, Carroll TM, Chen Y, Matson JA, Huang S, Mazzucco CE et al (2002) Core-modified sordaricin derivatives: synthesis and antifungal activity. Bioorg Med Chem Lett 12:3403-3405. https://doi.org/10.1016/S0960-894X(02) 00764-3

Rock FL, Mao W, Yaremchuk A, Tukalo M, Crépin T, Zhou H et al (2007) An antifungal agent inhibits an aminoacyl-tRNA synthetase by trapping tRNA in the editing site. Science 316:1759-1761. https://doi.org/10.1126/science.1142189

Rodrigues ML, Nosanchuk JD (2020) Fungal diseases as neglected pathogens: a wake-up call to public health officials. PLoS Neglect Trop D 14:e0007964. https://doi.org/10.1371/journ al.pntd.0007964

Rodrigues-Vendramini FAV, Marschalk C, Toplak M, Macheroux P, Bonfim-Mendonça PDS, Estivalet Svidzinski TIE et al (2019) Promising new antifungal treatment targeting chorismate synthase from Paracoccidioides brasiliensis. Antimicrob Agents Ch 63:e01097-e1118. https://doi.org/10.1128/AAC.01097-18

Rong-Mullins X, Ravishankar A, McNeal KA, Lonergan ZR, Biega AC, Creamer JP et al (2017) Genetic variation in Dip5, an amino acid permease, and Pdr5, a multiple drug transporter, regulates glyphosate resistance in S. cerevisiae. PLoS ONE 12:1-17. https://doi.org/10.1371/journal.pone.0187522

Rubio Gomez MA, Ibba M (2020) Aminoacyl-tRNA synthetases. RNA 26:910-936. https://doi.org/10.1261/rna.071720.119

Sagong HY, Kim KJ (2017) Structural insights into substrate specificity of cystathionine $\gamma$-synthase from Corynebacterium glutamicum. J Agric Food Chem 65:6002-6008. https://doi.org/ 10.1021/acs.jafc.7b02391

Sahu U, Rajendra VKH, Kapnoor SS, Bhagavat R, Chandra N, Rangarajan PN (2017) Methionine synthase is localized to the nucleus in Pichia pastoris and Candida albicans and to the cytoplasm in Saccharomyces cerevisiae. J Biol Chem 292:14730-14746. https://doi.org/10.1074/jbc.M117.783019

Serrano-Wu MH, St. Laurent DR, Carroll TM, Dodier M, Gao Q, Gill P et al (2003) Identification of a broad-spectrum azasordarin with improved pharmacokinetic properties. Bioorg Med Chem Lett 13:1419-1423. https://doi.org/10.1016/S0960894X(03)00161-6

Shao W, Yang Y, Zhang Y, Lv C, Ren W, Chen C (2016) Involvement of BcStr2 in methionine biosynthesis, vegetative differentiation, multiple stress tolerance and virulence in Botrytis cinerea. Mol Plant Pathol 17:438-447. https://doi.org/10.1111/mpp.12292

Sharma N, Sharma D (2015) An upcoming drug for onychomycosis: tavaborole. J Pharmacol Pharmacother 6:236-239. https://doi. org/10.4103/0976-500X.171870

Singh A, Sherman F (1974) Characteristics and relationships of mercury resistant mutants and methionine auxotrophs of yeast. J Bacteriol 118:911-918. https://doi.org/10.1128/jb.118.3.911918.1974

Singh S, Braus-Stromeyer SA, Timpner C, Tran VT, Lohaus G, Reusche M et al (2010) Silencing of Vlaro2 for chorismate synthase revealed that the phytopathogen Verticillium longisporum induces the cross-pathway control in the xylem. Appl Microbiol Biot 85:1961-1976. https://doi.org/10.1007/s00253-009-2269-0

Skrodenienė E, Dambrauskienė A, Vitkauskienè A (2006) Susceptibility of yeasts to antifungal agents in Kaunas University of Medicine Hospital. Medicina (kaunas) 42:294-299

Skwarecki AS, Schielmann M, Martynow D, Kawczyński M, Wiśniewska A, Milewska MJ et al (2018) Antifungal dipeptides incorporating an inhibitor of homoserine dehydrogenase. J Pept Sci 24:1-8. https://doi.org/10.1002/psc.3060

Snelders E, Van Der Lee HAL, Kuijpers J, Rijs AJM, Varga J, Samson RA et al (2008) Emergence of azole resistance in Aspergillus fumigatus and spread of a single resistance mechanism. PLoS Med 5:1629-1637. https://doi.org/10.1371/journal.pmed. 0050219

Sousa S, McLaughlin MM, Pereira SA, VanHorn S, Knowlton R, Brown JR et al (2002) The ARO4 gene of Candida albicans encodes a tyrosine-sensitive DAHP synthase: evolution, functional conservation and phenotype of Aro3p-, Aro4p-deficient mutants. Microbiology 148:1291-1303. https://doi.org/10. 1099/00221287-148-5-1291

Srivastava S, Chaudhary A, Mani A (2018) Identification of potential inhibitors for identified novel drug targets of Aspergillus fumigatus. In: International conference on bioinformatics and systems biology, pp. 81-84. https://doi.org/10.1109/BSB.2018. 8770655

Stop neglecting fungi (2017) Nat Microbiol 2:17120. https://doi.org/ 10.1038/nmicrobiol.2017.120

Sträter N, Schnappauf G, Braus G, Lipscomb WN (1997) Mechanisms of catalysis and allosteric regulation of yeast chorismate mutase from crystal structures. Structure 5:1437-1452. https://doi.org/ 10.1016/S0969-2126(97)00294-3

Su H, Han L, Ding N, Guan P, Hu C, Huang X (2018) Bafilomycin $\mathrm{C} 1$ exert antifungal effect through disturbing sterol biosynthesis in Candida albicans. J Antibiot 71:467-476. https://doi.org/10. 1038/s41429-017-0009-8

Su H, Hu C, Cao B, Qu X, Guan P, Mu Y et al (2020) A semisynthetic borrelidin analogue $\mathrm{BN}-3 \mathrm{~b}$ exerts potent antifungal activity against Candida albicans through ROS-mediated oxidative damage. Sci Rep-UK 10:1-12. https://doi.org/10.1038/ s41598-020-61681-0

Suliman HS, Appling DR, Robertus JD (2007) The gene for cobalamin-independent methionine synthase is essential in Candida albicans: a potential antifungal target. Arch Biochem Biophys 467:218-226. https://doi.org/10.1016/j.abb.2007.09.003

Tang W, Jiang H, Zheng Q, Chen X, Wang R, Yang S et al (2019) Isopropylmalate isomerase MoLeul orchestrates leucine biosynthesis, fungal development, and pathogenicity in Magnaporthe oryzae. Appl Microbiol Biot 103:327-337. https://doi.org/10. 1007/s00253-018-9456-9

Toh-e A, Ohkusu M, Shimizu K, Ishiwada N, Watanabe A, Kamei K (2018) Novel biosynthetic pathway for sulfur amino acids in Cryptococcus neoformans. Curr Genet 64:681-696. https://doi. org/10.1007/s00294-017-0783-7 
Tournu H, Butts A, Palmer GE (2019) Titrating gene function in the human fungal pathogen Candida albicans through poly-adenosine tract insertion. mSphere 4:1-12. https://doi.org/10.1128/ msphere.00192-19

Tsai PW, Chien CY, Yeh YC, Tung L, Chen HF, Chang TH et al (2017) Candida albicans Hom6 is a homoserine dehydrogenase involved in protein synthesis and cell adhesion. J Microbiol Immunol Infect 50:863-871. https://doi.org/10.1016/j.jmii.2016.03.001

Tscherner M, Kuchler K (2019) A histone acetyltransferase inhibitor with antifungal activity against CTG clade Candida species. Microorganisms 7:201. https://doi.org/10.3390/microorganisms7 070201

Tu Y, Kreinbring CA, Hill M, Liu C, Petsko GA, McCune CD et al (2018) Crystal structures of cystathionine $\beta$-synthase from Saccharomyces cerevisiae: one enzymatic step at a time. Biochemistry-US 57:3134-3145. https://doi.org/10.1021/acs.biochem. 8b00092

Ubhi D, Kago G, Monzingo AF, Robertus JD (2014) Structural analysis of a fungal methionine synthase with substrates and inhibitors. J Mol Biol 426:1839-1847. https://doi.org/10.1016/j.jmb.2014. 02.006

Van den Bossche H, Willemsens G, Cools W, Marichal P, Lauwers W (1983) Hypothesis on the molecular basis of the antifungal activity of N-substituted imidazoles and triazoles. Biochem Soc T 11:665-667. https://doi.org/10.1042/bst0110665

van der Weerden NL, Anderson MA (2013) Plant defensins: common fold, multiple functions. Fungal Biol Rev 26:121-131

van Paassen J, Russcher A, in't Veld-van Wingerden AW, Verweij PE, Kuijper EJ (2016) Emerging aspergillosis by azole-resistant Aspergillus fumigatus at an intensive care unit in the Netherlands, 2010 to 2013. Eurourveillance 21:1560-7917. https://doi.org/10. 2807/1560-7917.ES.2016.21.30.30300

Velivelli SLS, Czymmek KJ, Li H et al (2020) Antifungal symbiotic peptide NCR044 exhibits unique structure and multifaceted mechanisms of action that confer plant protection. Proc Natl Acad Sci USA 117:16043-16054. https://doi.org/10.1073/pnas. 2003526117

Verweij PE, Chowdhary A, Melchers WJG, Meis JF (2016) Azole resistance in Aspergillus fumigatus: can we retain the clinical use of mold-active antifungal azoles? Clin Infect Dis 62:362-368. https://doi.org/10.1093/cid/civ885

Viaene J, Tiels P, Logghe M, Dewaele S, Martinet W, Contreras R (2000) MET15 as a visual selection marker for Candida albicans. Yeast 16:1205-1215. https://doi.org/10.1002/1097-0061(20000 930)16:13\%3c1205::AID-YEA615\%3e3.0.CO;2-C

Viola RE, Thangavelu B, Mutthamsetty V, Bhansali P (2019) Potent phthalate inhibitors of aspartate $\mathrm{N}$-acetyltransferase and selective aspartate pathway inhibitors. U.S. Pat. No 10449168B2. https:// worldwide.espacenet.com/patent/search/family/058188153/publi cation/US10449168B2?q=pn\%3DUS10449168B2. Accessed 30 Apr 2020

Wang BL, Zhang LY, Liu XH, Ma Y, Zhang Y, Li ZM et al (2017) Synthesis, biological activities and SAR studies of new 3-substitutedphenyl-4-substitutedbenzylideneamino-1,2,4-triazole Mannich bases and bis-Mannich bases as ketol-acid reductoisomerase inhibitors. Bioorg Med Chem Lett 27:5457-5462. https://doi.org/ 10.1016/j.bmcl.2017.10.065

Wassano NS, Leite AB, Reichert-Lima F, Schreiber AZ, Moretti NS, Damasio A (2020) Lysine acetylation as drug target in fungi: an underexplored potential in Aspergillus spp. Braz J Microbiol 51:673-683. https://doi.org/10.1007/s42770-020-00253-w

Wei W, Cheng D, Liu J, Li Y, Ma Y, Li Y et al (2016) Design, synthesis and SAR study of novel sulfonylureas containing an alkenyl moiety. Org Biomol Chem 14:8356-8366. https://doi.org/10. 1039/c6ob01555g
Wei C, Qin T, Li Y, Wang W, Dong T, Wang Q (2020) Host-induced gene silencing of the acetolactate synthases VdILV2 and VdILV6 confers resistance to Verticillium wilt in cotton (Gossypium hirsutum L.). Biochem Biophys Res Co 524:392-397. https://doi. org/10.1016/j.bbrc.2020.01.126

Weinberg RA, McWherter CA, Freeman SK, Wood DC, Gordon JI, Lee SC (1995) Genetic studies reveal that myristoylCoA:protein $\mathrm{N}$-myristoyltransferase is an essential enzyme in Candida albicans. Mol Microbiol 16:241-250. https://doi.org/10.1111/j.13652958.1995.tb02296.x

Wiederhold NP (2017) Antifungal resistance: current trends and future strategies to combat. Infect Drug Resist 10:249-259. https://doi. org/10.2147/IDR.S124918

Wilkinson B, Gregory MA, Moss SJ, Carletti I, Sheridan RM, Kaja A et al (2006) Separation of anti-angiogenic and cytotoxic activities of borrelidin by modification at the $\mathrm{C} 17$ side chain. Bioorganic Med Chem Lett 16:5814-5817. https://doi.org/10.1016/j.bmcl. 2006.08.073

Wong JH, Ng TB (2005) Vulgarinin, a broad-spectrum antifungal peptide from haricot beans (Phaseolus vulgaris). Int J Biochem Cell Biol 37:1626-1632. https://doi.org/10.1016/j.biocel.2005.02.022

Wong JH, Zhang XQ, Wang HX, Ng TB (2006) A mitogenic defensin from white cloud beans (Phaseolus vulgaris). Peptides 27:20752081. https://doi.org/10.1016/j.peptides.2006.03.020

Wu Y, Dockendorff C (2018) Synthesis of a novel bicyclic scaffold inspired by the antifungal natural product sordarin. Tetrahedron Lett 59:3373-3376. https://doi.org/10.1016/j.tetlet.2018.07.064

Wu Y, Dockendorff C (2019) Synthesis of simplified azasordarin analogs as potential antifungal agents. J Org Chem 84:5292-5304. https://doi.org/10.1021/acs.joc.9b00296

Wu RJ, Ren T, Gao JY, Wang L, Yu Q, Yao Z et al (2019) Chemical preparation, biological evaluation and 3D-QSAR of ethoxysulfuron derivatives as novel antifungal agents targeting acetohydroxyacid synthase. Eur J Med Chem 162:348-363. https://doi. org/10.1016/j.ejmech.2018.11.005

Xu H, Hou Z, Liang Z, Guo MB, Su X, Guo C (2019) Design, synthesis and antifungal activity of benzofuran and its analogues. Chin $\mathrm{J}$ Chem 37:1245-1250. https://doi.org/10.1002/cjoc.201900304

Yadav AK, Desai PR, Rai MN, Kaur R, Ganesan K, Bachhawat AK (2011) Glutathione biosynthesis in the yeast pathogens Candida glabrata and Candida albicans: Essential in C. glabrata, and essential for virulence in C. albicans. Microbiology 157:484495. https://doi.org/10.1099/mic.0.045054-0

Yadav S, Lim SM, Ramasamy K, Vasudevan M, Shah SAA, Mathur A et al (2018) Synthesis and evaluation of antimicrobial, antitubercular and anticancer activities of 2-(1-benzoyl-1H-benzo[d] imidazol-2-ylthio)-N-substituted acetamides. Chem Cent J 12:114. https://doi.org/10.1186/s13065-018-0432-3

Yamaguchi H, Uchida K, Hiratani T, Nagate T, Watanabe N, Omura S (1988) RI-331, a new antifungal antibiotic. Ann NY Acad Sci 544:188-190. https://doi.org/10.1111/j.1749-6632.1988.tb404 03.x

Yamaguchi H, Yamaguchi M, Tsuruo T (1992) Mechanism of action of an antifungal antibiotic, RI-331, (S) 2-amino-4-oxo-5-hydroxypentanoic acid; kinetics of inactivation of homoserine dehydrogenase from Saccharomyces cerevisiae. J Antibiot 45:750-755. https://doi.org/10.7164/antibiotics.45.750

Yamaki H, Yamaguchi M, Imamura H, Suzuki H, Nishimura T, Saito $\mathrm{H}$ et al (1990) The mechanism of antifungal action of (S)2-amino-4-oxo-5-hydroxypentanoic acid, RI-331: the inhibition of homoserine dehydrogenase in Saccharomyces cerevisiae. Biochem Biophys Res Co 168:837-843. https://doi.org/10.1016/ 0006-291X(90)92397-I

Yan Y, Liu Q, Zang X, Yuan S, Bat-Erdene U, Nguyen C et al (2018) Resistance-gene-directed discovery of a natural-product 
herbicide with a new mode of action. Nature 559:415-418. https://doi.org/10.1038/s41586-018-0319-4

Ye XY, Ng TB (2001) Peptides from pinto bean and red bean with sequence homology to cowpea 10-kDa protein precursor exhibit antifungal, mitogenic, and HIV-1 reverse transcriptase-inhibitory activities. Biochem Biophys Res Commun 285:424-429. https:// doi.org/10.1006/bbrc.2001.5194

Yeh YC, Wang HY, Lan CY (2018) Candida albicans Aro1 affects cell wall integrity, biofilm formation and virulence. J Microbiol Immunol Infect 53:115-124. https://doi.org/10.1016/j.jmii.2018. 04.002

Yu MJ, Wu J, Chen SL (2020) Mechanism and inhibitor exploration with binuclear $\mathrm{Mg}$ ketol-acid reductoisomerase: targeting the biosynthetic pathway of branched-chain amino acids. Chem Bio Chem 21:381-391. https://doi.org/10.1002/cbic.201900363

Zawahir S, Roberts DM, Palangasinghe C, Mohamed F, Eddleston M, Dawson AH et al (2009) Acute intentional self-poisoning with a herbicide product containing fenoxaprop-P-ethyl, ethoxysulfuron, and isoxadifen ethyl: A prospective observational study. Clin Toxicol 47:792-797. https://doi.org/10.1080/1556365090 3174810
Zhang P, Ma S (2019) Recent development of leucyl-tRNA synthetase inhibitors as antimicrobial agents. Med Chem Commun 10:13291341. https://doi.org/10.1039/c9md00139e

Zhang MQ, Xu KX, Xue Y, Cao F, Yang LJ, Hou XM et al (2019) Sordarin diterpene glycosides with an unusual 1,3-dioxolan-4-one ring from the zoanthid-derived fungus Curvularia hawaiiensis TA26-15. J Nat Prod 82:2477-2482. https://doi.org/10.1021/acs. jnatprod.9b00164

Zhong Y, Han X, Li S, Qi H, Song Y, Qiao X (2017) Design, synthesis, antifungal activity and molecular docking of thiochroman-4-one derivatives. Chem Pharm Bull 65:904-910. https://doi.org/10. 1248/cpb.c17-00274

Publisher's Note Springer Nature remains neutral with regard to jurisdictional claims in published maps and institutional affiliations. 